Canadian

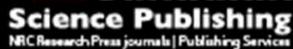

Canadian Geotechnical Journal Revue canadienne de géotechnique

\title{
A rigorous method for three-dimensional asymmetrical slope stability analysis
}

\begin{tabular}{|r|l|}
\hline Journal: & Canadian Geotechnical Journal \\
\hline Manuscript ID & cgj-2017-0317.R1 \\
\hline Manuscript Type: & Article \\
\hline Date Submitted by the Author: & 18-Jul-2017 \\
\hline Complete List of Authors: & $\begin{array}{l}\text { Jiang, Qinghui; Wuhan University, } \\
\text { Zhou, Chuang Bing; Wuhan University }\end{array}$ \\
\hline Keyword: & $\begin{array}{l}\text { slope stability, three-dimensional analysis, limit equilibrium method, factor } \\
\text { of safety, direction of sliding }\end{array}$ \\
\hline \multicolumn{2}{|l}{} \\
\hline
\end{tabular}

SCHOLARONE ${ }^{\text {IM }}$

Manuscripts 


\title{
A rigorous method for three-dimensional asymmetrical slope stability analysis
}

\author{
Qinghui Jiang $^{1,2^{*}} \quad$ Chuangbing Zhou ${ }^{1,2}$
}

1. School of Civil Engineering and Architecture, Nanchang University, Nanchang 330031, P. R. China

2. School of Civil Engineering, Wuhan University, Wuhan 430072, P. R. China

*Corresponding author

Address: School of Civil Engineering and Architecture, Nanchang University, Nanchang 330031, P. R. China

E-mail: jqh1972@whu.edu.cn

Telephone: +86-27-68772221 
Abstract: Most slope failures exhibit remarkable asymmetrical variation in the transverse direction. A rigorous method satisfying all the six equilibrium conditions is proposed for evaluating 3-d asymmetrical slope stability. Since there is no need to predefine a symmetrical plane in this analysis, the method is applicable to slopes with complex geometries, geologies, and loading conditions. The proposed method can not only calculate the factor of safety, but also predict the direction of sliding of the potential failure mass. Global equilibrium equations are formulated in the light of the safety factor, sliding direction, and an assumed distribution of normal stress on the slip surface. The Newton method is then used to solve these equations, which has been proven to enjoy both a large range of convergence and a fast convergence rate. Thereafter, physical admissibility conditions of the solutions, and the effects of the size of discretised columns on solution accuracy, are discussed in the present 3-d analysis. The method is validated by using five typical examples documented in the literature. The failure of the Kettleman waste landfill slope is also re-evaluated using the proposed method. The calculated stability and direction of sliding match field observations.

Key words: slope stability; three-dimensional analysis; limit equilibrium method; factor of safety; direction of sliding 


\section{Introduction}

Most failure surfaces of slopes present remarkable asymmetrical variation in the out-of-plane direction (Hungr et al. 1989; Chen et al. 2001; Griffiths and Marquez 2007); however, 2-d limit equilibrium methods are usually adopted to evaluate the stability of slopes or landslides. In the design of landslide reinforcement, geotechnical engineers usually select a "representative section" (the so-called most dangerous section), to conduct mechanical analyses. However, strictly speaking, the geometry, properties, or loading conditions of a landslide vary in the transverse direction, so that 2-d analyses may lead to conservative treatment and consequently, a waste of resources. On the other hand, the 2-d back-analysis of a failed slope will result in an unconservative overestimation of the soil shear strength. In addition, due to human subjectivity in the selection of the "representative section", it may not be the most dangerous section, and thus engender a hidden risk to the design of remediation measures. Therefore, it is necessary, for practical application, to develop 3-d methods, and their corresponding computer programs, for the stability assessment of slopes or landslides.

While more and more sophisticated numerical methods such as the finite element methods have been applied successfully in the stability evaluation of slopes, the conventional limit equilibrium method still plays a major role in the design of slopes due to its clear concept and simple parameter inputs (Sarma and Tan 2006; Zheng 2012; Jiang et al 2013). In recent years, there have been a number of 3-d limit equilibrium methods (LEM) developed for slope, or landslide, stability analysis: these 
have been presented on the basis of extensions of corresponding 2-d methods (Chen and Chameau 1982; Baker and Leshchinsky 1987; Zhang 1988; Hungr et al. 1989; Leshchinsky and Huang 1992; Lam and Fredlund 1993; Zheng 2012; Sun et al. 2012; Zhou and Cheng 2013). Since a symmetric plane, or sliding direction, needs to be pre-determined in the analysis, these 3-d methods are only appropriate for landslides with a symmetrical geometry.

Asymmetrical conditions induced by variable soil and rock stratigraphy, external loading, and other factors are often found (Huang and Tsai 2000). To solve such asymmetrical problems, Yamagami and Jiang $(1996,1997)$ presented their 3-d limit equilibrium method in which the sliding direction is determined by searching for the minimum factor of safety in relation to the rotation of the three coordinate axes. Based on two-directional moment equilibrium conditions, Huang and Tsai (2000) developed a simplified version of Bishop's method to evaluate the stability of asymmetrical slopes with spherical failure surfaces. Huang et al. (2002) further proposed a generalised method for 3-d slope analysis with failure surfaces of arbitrary shape, which meets two-directional force and moment equilibrium conditions. In both Huang's simplified, and generalised methods, different sliding directions for individual columns are assumed at the limit state. This assumption may be in conflict with the definition of the rigid failure body of LEM, which results in numerical convergence problems under transverse loading. To overcome this limitation, Cheng and Yip (2007) developed 3-d asymmetrical slope stability models by extensions of Bishop's simplified, Janbu's simplified, and the Morgenstern-Price, methods based on 
a unique sliding direction assumption for all columns. By adopting the same assumption from Cheng and Yip, Kalatehjari et al. (2015) reformulated Huang's model to calculate this unique sliding direction. It is noteworthy that the aforementioned methods for asymmetrical slopes, or landslides, can only meet some of the necessary equilibrium conditions, and as such, are classified as non-rigorous methods. Since the situations in 3-d analyses are much more complicated, rigorous 3-d methods are necessary to give a reliable estimate of landslide stability (Zheng 2012).

In rigorous 3-d methods for slope stability analysis, all six equilibrium conditions (three directional force and three moment equilibrium equations) should be satisfied for the potential failure mass. So far, a few investigative results on rigorous 3-d limit equilibrium methods have been reported. Zheng $(2009,2012)$ proposed rigorous 3-d models satisfying all equilibrium conditions based on extensions of corresponding 2-d Bell's method and the Morgenstern-Price method. Zhou and Cheng (2013) developed their rigorous 3-d method by neglecting all horizontal inter-column shear forces. The Zhou-Cheng method can also be applied to search for the critical ellipsoidal sliding surface. However, the direction of sliding of the failure mass needs to be known in advance in both Zheng's, and the Zhou-Cheng, methods. For a slope/landslide with asymmetrical geometry and loading conditions, it is very difficult to judge exactly the direction of sliding of the potential failure mass. Due to this disadvantage, their methods are still of limited use in practical problems.

From the above review, there are two major limitations in most available $3-d$ 
limit equilibrium methods for slope or landslide stability analysis, which are: (1) a "guessed" direction of sliding or plane of symmetry is prescribed in advance; (2) only a part of the equilibrium conditions is satisfied for asymmetrical landslide stability analysis. The purpose of this study is to develop a rigorous limit equilibrium method for 3-d asymmetrical slopes/landslides with complex geometries and geological conditions. All six equilibrium conditions (three force-equilibrium and three moment-equilibrium conditions) are strictly satisfied in the proposed method. The sliding direction can be determined based on force and moment equilibrium conditions instead of being guessed in advance. The proposed method is also applicable to the stability analysis of slopes, or landslides, with a symmetrical failure surface. The resulting direction of sliding agrees well with the direction of the symmetrical plane.

\section{Basic Assumptions}

\section{Unique direction of sliding}

Fig. 1a shows a potential failure mass $\Omega$ with a general-shaped failure surface $S$. Note that the symmetrical, or asymmetrical, failure surfaces are taken as general surfaces in this framework, for general purposes. For 3-d analysis, the failure mass is divided into a number of columns with vertical interfaces. Fig. $1 \mathrm{~b}$ shows the plan view of the slip surface and columns. A significant feature of 3-d asymmetrical landslide stability analysis is the direction of sliding (DOS). The DOS is defined as an angle calculated anticlockwise from the positive $x$-axis to the route of sliding which 
shows the direction of movement of the failure mass in the $x-y$ plane (Fig. 1b). When close to failure, the DOS can occupy one of three states: (1) Soil columns are moving in the same direction with a unique sliding behaviour; (2) Soil columns are moving towards each other; and (3) Soil columns are moving away from each other (Cheng and Yip 2007). According to the basic principle of the limit equilibrium methods, the failure mass is considered as a rigid mass in a limit equilibrium state. The second, and third, possibilities of the DOS violate the assumption of rigid mass behaviour. Consequently, the first possibility with a unique DOS may be applicable to 3-d limit equilibrium analysis and is adopted in the present formulation. With reference to Fig. $1 \mathrm{~b}$, all columns are assumed to have the same direction of sliding, denoted as $\beta$, on the plan view of the failure mass.

A vertical differential column with a base area of $\mathrm{d} S$ in the failure mass $\Omega$ is selected for analysis, as shown in Fig. 2a. The base of the column is represented by the plane with dip angles, $\alpha_{x}$ and $\alpha_{y}$, with respect to $x$ - and $y$-axes, respectively. From Huang and Tsai (2000), the unit normal vector $\mathbf{n}$ of the column base pointing to the inner area of $\Omega$ can be expressed as:

$$
\begin{aligned}
\mathbf{n} & =\left[\begin{array}{lll}
n_{x} & n_{y} & n_{z}
\end{array}\right]^{\mathrm{T}} \\
& =\left[\begin{array}{lll}
-\tan \alpha_{x} / J & -\tan \alpha_{y} / J & 1 / J
\end{array}\right]^{\mathrm{T}}
\end{aligned}
$$

where $J=\sqrt{1+\tan ^{2} \alpha_{x}+\tan ^{2} \alpha_{y}}$.

Let $\mathbf{s}=\left[\begin{array}{lll}s_{x} & s_{y} & s_{z}\end{array}\right]^{\mathrm{T}}$ be unit vector of the mobilised shear force acting on the column base (Fig. 2). The projection of $\mathbf{s}$ on the $x-y$ plane $\mathbf{s}^{\prime}$, is parallel to the direction of sliding because the direction of the shear force over the slip surface is 
opposite to the sliding direction. According to the assumption of a unique DOS, the projected shear angle (the angle between $\mathbf{s}^{\prime}$ and the $x$-axis) of the shear forces over the slip surface is same for all columns in the $x-y$ plane, and equals the sliding direction angle $\beta$. With reference to Fig. $2 \mathrm{~b}$, the direction cosines of the shear force at the column base can be described as:

$$
s_{x}=\sin \theta \cos \beta, s_{y}=\sin \theta \sin \beta, s_{z}=\cos \theta
$$

where $\theta$ is the angle between the shear force at the column base and the vertical.

Since the direction of the mobilised shear force is perpendicular to $\mathbf{n}$, we have:

$$
\sin \theta \cos \beta\left(-\tan \alpha_{x}\right)+\sin \theta \sin \beta\left(-\tan \alpha_{y}\right)+\cos \theta=0
$$

By solving Eq. (3), the unit vector $\mathbf{s}$ of the shear force on the column base can be readily determined as follows:

$$
\begin{aligned}
\mathbf{S} & =\left[\begin{array}{lll}
s_{x} & s_{y} & s_{z}
\end{array}\right]^{\mathrm{T}} \\
& =\left[\begin{array}{ll}
\cos \beta / J^{\prime} & \sin \beta / J^{\prime} \quad\left(\cos \beta \tan \alpha_{x}+\sin \beta \tan \alpha_{y}\right) / J^{\prime}
\end{array}\right]^{\mathrm{T}}
\end{aligned}
$$

where $J^{\prime}=\sqrt{1+\left(\tan \alpha_{x} \cos \beta+\tan \alpha_{y} \sin \beta\right)^{2}}$.

\section{Distribution of normal stress on slip surface}

Now we consider the external and internal forces acting on a differential column, as shown in Fig. 2a: $\sigma \mathbf{n d} S$ and $\tau \mathbf{s d} S$ are the normal force and shear force acting on the column base, respectively. $-\mathbf{k} \mathrm{d} w$ and $\mathbf{e} k_{c} \mathrm{~d} w$ represent the gravity and the seismic force acting on the column, respectively; $\mathrm{dp}$ is the resultant of all inter-column forces acting on the row-interfaces ABFE and DCGH, and $\mathrm{dq}$ is the resultant of the inter-column forces acting on the column-interfaces ADHE and BCGF. 
Here, $\mathbf{k}$ is a unit vector in the vertical ( $z$-axis) direction; $k_{c}$ is a seismic coefficient; and $\mathbf{e}$ is a unit vector in the direction of the horizontal seismic force.

The force equilibrium equations for the column can be expressed as follows:

$$
\sigma \mathbf{n} \mathrm{d} S+\tau \mathbf{s} \mathrm{d} S-\mathbf{k d} w+\mathbf{e} k_{c} \mathrm{~d} w+\mathrm{d} \mathbf{p}+\mathrm{d} \mathbf{q}=0
$$

According to the dot product of the Eq. (5) and $\mathbf{n}$, we have

$$
\sigma=n_{z} \frac{\mathrm{d} w}{\mathrm{~d} S}-\mathbf{n} \cdot \mathbf{e} \frac{k_{c} \mathrm{~d} w}{\mathrm{~d} S}-\mathbf{n} \cdot \frac{\mathrm{d} \mathbf{p}}{\mathrm{d} S}-\mathbf{n} \cdot \frac{\mathrm{d} \mathbf{q}}{\mathrm{d} S}
$$

Considering that

$$
d w=\bar{\gamma} h n_{z} \mathrm{~d} S
$$

where $\bar{\gamma}$ and $h$ are the average unit weight and height of the soil column, respectively.

Substituting Eq. (7) into Eq. (6), we obtain

$$
\sigma=\sigma_{\mathrm{ext}}+\sigma_{\mathrm{int}}
$$

where $\sigma_{\text {ext }}$ represents the contribution of the external forces acting on the column to $\sigma$, and equals

$$
\sigma_{\text {ext }}=n_{z}\left(n_{z}-\mathbf{n} \cdot \mathbf{e} k_{\mathrm{c}}\right) \bar{\gamma} h
$$

$\sigma_{\text {int }}$ represents the contribution of the inter-column forces acting on the column to

$\sigma$ and is statically indeterminate, and equal to

$$
\sigma_{\text {int }}=-\mathbf{n} \cdot \frac{\mathrm{d} \mathbf{p}+\mathrm{d} \mathbf{q}}{\mathrm{d} S}
$$

According to Eq. (8), we can construct an approximation to $\sigma$ as follows:

$$
\sigma=\sigma_{\text {ext }}+\xi(x, y ; \lambda)
$$

where $\xi$ is a function in the horizontal coordinate pair of $(x, y)$ with an unknown 
fourth-order vector $\lambda$. The reason for introducing four unknowns lies in that the six equilibrium conditions for the failure mass are able to solve, at most, six unknowns: the safety factor and sliding direction account for a further two unknowns.

There are many choices of $\xi$. In this study, we use a polynomial function to construct $\xi$. Letting the polynomial basis $\quad \mathbf{r}=\left(\begin{array}{llll}1 & x & y & x y\end{array}\right)^{\mathrm{T}}$, we have

$$
\xi(x, y ; \lambda)=\mathbf{r}^{\mathrm{T}} \lambda
$$

Therefore, the total normal stress on the failure surface is approximated by

$$
\sigma=\sigma_{\text {ext }}+\mathbf{r}^{\mathrm{T}} \lambda
$$

\section{Global equilibrium equations for the failure mass}

Assuming that the potential failure mass is divided into $n$ columns with vertical interfaces. According to Eq. (13), the normal force on the base of the $i$ th column can be written as:

$$
N_{i}=\sigma_{\mathrm{ext}}^{i} A_{i}+\left(\lambda_{1}+\lambda_{2} x_{i}^{b}+\lambda_{3} y_{i}^{b}+\lambda_{4} x_{i}^{b} y_{i}^{b}\right) A_{i}
$$

where $A_{i}$ represents the base area of the $i$ th column, and $\left(x_{i}^{b}, y_{i}^{b}\right)$ represents the horizontal coordinates of the centre of the base of the $i$ th column.

As in most other limit equilibrium methods, a constant factor of safety is assumed everywhere along the failure surface. The Mohr-Coulomb criterion implies that the shear force on the base of the $i$ th column is:

$$
S_{i}=\frac{1}{F}\left[\left(N_{i}-u A_{i}\right) f_{e}+c_{e} A_{i}\right]
$$

where $F$ is the factor of safety, $f_{e}$ and $c_{e}$ are the shear strength parameters in terms of effective stress, and $u$ is pore pressure on the base of the column. 
The inter-column forces acting on the vertical interfaces of the discretised columns occur in pairs and are cancelled during the summation of forces, or moments, in the system equilibrium equations. Consequently, the equilibrium equations for the failure mass comprise only external forces. The global force equilibrium equations can be written in vector form as:

$$
\sum_{i=1}^{n} N_{i} \mathbf{n}_{i}+\sum_{i=1}^{n} S_{i} \mathbf{s}_{i}+\sum_{i=1}^{n}\left(-\mathbf{k} w_{i}+\mathbf{e} k_{c} w_{i}\right)=0
$$

The global moment equilibrium equations can be written in vector form as:

$$
\sum_{i=1}^{n} N_{i}\left(\mathbf{x}_{i}^{b} \times \mathbf{n}_{i}\right)+\sum_{i=1}^{n} S_{i}\left(\mathbf{x}_{i}^{b} \times \mathbf{s}_{i}\right)+\sum_{i=1}^{n}\left[-w_{i}\left(\mathbf{x}_{i}^{m} \times \mathbf{k}\right)+k_{c} w_{i}\left(\mathbf{x}_{i}^{m} \times \mathbf{e}\right)\right]=0
$$

where $w_{i}$ is the weight of the $i$ th column, $\mathbf{x}_{i}^{b}$ represents the coordinates of the centre of the base of the $i$ th column, and $\mathbf{x}_{i}^{m}$ represents the coordinates of the centre of mass of the $i$ th column.

Substituting Eq. (15) into Eqs (16) and (17), gives:

$$
\begin{aligned}
& \sum_{i=1}^{n} N_{i}\left(F \mathbf{n}_{i}+f_{e} \mathbf{s}_{i}\right)+\sum_{i=1}^{n}\left(c_{e}-u f_{e}\right) A_{i} \mathbf{s}_{i}+F \mathbf{f}=0 \\
& \sum_{i=1}^{n} N_{i}\left[F\left(\mathbf{x}_{i}^{b} \times \mathbf{n}_{i}\right)+f_{e}\left(\mathbf{x}_{i}^{b} \times \mathbf{s}_{i}\right)\right]+\sum_{i=1}^{n}\left(c_{e}-u f_{e}\right) A_{i}\left(\mathbf{x}_{i}^{b} \times \mathbf{s}_{i}\right)+F \mathbf{m}=0
\end{aligned}
$$

where $\mathbf{f}$ and $\mathbf{m}$ represent the resultant of external forces acting on the failure mass and resultant moment of the external forces about the coordinate axes, written as:

$$
\begin{aligned}
& \mathbf{f}=\sum_{i=1}^{n}\left(-\mathbf{k} w_{i}+\mathbf{e} k_{c} w_{i}\right) \\
& \mathbf{m}=\sum_{i=1}^{n}\left[-w_{i}\left(\mathbf{x}_{i}^{m} \times \mathbf{k}\right)+k_{c} w_{i}\left(\mathbf{x}_{i}^{m} \times \mathbf{e}\right)\right]
\end{aligned}
$$

Eqs (18) and (19) can be rewritten in a more compact form as follows: 


$$
\mathbf{g}(\boldsymbol{\lambda}, \beta, F)=\sum_{i=1}^{n} N_{i}\left(F \mathbf{n}_{i}^{\prime}+f_{e} \mathbf{s}_{i}^{\prime}\right)+\sum_{i=1}^{n}\left(c_{e}-u f_{e}\right) A_{i} \mathbf{s}_{i}^{\prime}+F \mathbf{f}^{\prime}=0
$$

where $\mathbf{g}$ denotes the vector of unbalanced forces and moments. $\mathbf{n}^{\prime}, \mathbf{s}^{\prime}$ and $\mathbf{f}^{\prime}$ are three sixth-order vectors, defined by:

$$
\mathbf{n}^{\prime}=\left(\begin{array}{c}
\mathbf{n} \\
\mathbf{x}^{b} \times \mathbf{n}
\end{array}\right), \quad \mathbf{s}^{\prime}=\left(\begin{array}{c}
\mathbf{s} \\
\mathbf{x}^{b} \times \mathbf{s}
\end{array}\right), \quad \mathbf{f}^{\prime}=\left(\begin{array}{c}
\mathbf{f} \\
\mathbf{m}
\end{array}\right)
$$

There are six unknowns, namely $\lambda, \beta$, and $F$ involved in the system described by (21). They can be efficiently solved by application of the Newton method. For application of the Newton method, the Jacobian of function $\mathbf{g}(\lambda, \beta, F)$ is needed and is defined as:

$$
\mathbf{J}=\left[\begin{array}{llllll}
\frac{\partial \mathbf{g}}{\partial \lambda_{1}} & \frac{\partial \mathbf{g}}{\partial \lambda_{2}} & \frac{\partial \mathbf{g}}{\partial \lambda_{3}} & \frac{\partial \mathbf{g}}{\partial \lambda_{4}} & \frac{\partial \mathbf{g}}{\partial \beta} & \frac{\partial \mathbf{g}}{\partial F}
\end{array}\right]
$$

All components of the Jacobian matrix $\mathbf{J}$ can be calculated as follows:

$$
\begin{aligned}
& \frac{\partial \mathbf{g}}{\partial \lambda_{j}}=\sum_{i=1}^{n} \frac{\partial N_{i}}{\partial \lambda_{j}}\left(F \mathbf{n}_{i}^{\prime}+f_{e} \mathbf{s}_{i}^{\prime}\right) \quad(j=1, \cdots, 4) \\
& \frac{\partial \mathbf{g}}{\partial \beta}=\sum_{i=1}^{n}\left(f_{e} N_{i}+c_{e} A_{i}-u f_{e} A_{i}\right) \frac{\partial \mathbf{s}_{i}^{\prime}}{\partial \beta} \\
& \frac{\partial \mathbf{g}}{\partial F}=\mathbf{f}^{\prime}+\sum_{i=1}^{n} N_{i} \mathbf{n}_{i}^{\prime}
\end{aligned}
$$

where

$$
\begin{aligned}
& \frac{\partial N_{i}}{\partial \lambda_{1}}=A_{i}, \frac{\partial N_{i}}{\partial \lambda_{2}}=A_{i} x_{i}^{b}, \frac{\partial N_{i}}{\partial \lambda_{3}}=A_{i} y_{i}^{b}, \frac{\partial N_{i}}{\partial \lambda_{4}}=A_{i} x_{i}^{b} y_{i}^{b} \\
& \frac{\partial \mathbf{s}_{i}^{\prime}}{\partial \beta}=\left(\begin{array}{c}
\frac{\partial \mathbf{s}_{i}}{\partial \beta} \\
\mathbf{x}_{i}^{b} \times \frac{\partial \mathbf{s}_{i}}{\partial \beta}
\end{array}\right)
\end{aligned}
$$


Here, the derivatives of $\mathbf{s}_{i}$ can be obtained from Eq. (4), and are expressed as

$$
\begin{aligned}
& \frac{\partial s_{x i}}{\partial \beta}=\frac{-\sin \beta+s_{x i} s_{y i} \tan \alpha_{x i}-s_{x i}^{2} \tan \alpha_{y i}}{J_{i}^{\prime}} \\
& \frac{\partial s_{y i}}{\partial \beta}=\frac{\cos \beta-s_{x i} s_{y i} \tan \alpha_{y i}+s_{y i}^{2} \tan \alpha_{x i}}{J_{i}^{\prime}} \\
& \frac{\partial s_{z i}}{\partial \beta}=\frac{\left(s_{x i} \tan \alpha_{y i}-s_{y i} \tan \alpha_{x i}\right)\left(J_{i}^{\prime}-s_{z i}\right)}{J_{i}^{\prime}}
\end{aligned}
$$

The six equations in the system described by (21) are functionally independent, so the Jacobian of $\mathbf{g}(\boldsymbol{\lambda}, \beta, F)$ is invertible for any $(\boldsymbol{\lambda}, \beta, F)$. Assuming that values of $\lambda, \beta$, and $F$ at the $k$ th step are obtained as $\lambda_{k}, \beta_{k}$, and $F_{k}$, then their values at the $(k+1)$ th step are modified to

$$
\left(\begin{array}{l}
\lambda_{k+1} \\
\beta_{k+1} \\
F_{k+1}
\end{array}\right)=\left(\begin{array}{l}
\lambda_{k} \\
\beta_{k} \\
F_{k}
\end{array}\right)-\left[\mathbf{J}\left(\boldsymbol{\lambda}_{k}, \beta_{k}, F_{k}\right)\right]^{-1} \mathbf{g}\left(\boldsymbol{\lambda}_{k}, \beta_{k}, F_{k}\right)
$$

The convergence criterion for $\lambda, \beta$ and $F$ can be defined as

$$
\zeta=\left\|\left(\lambda_{k+1}^{\mathrm{T}}, \beta_{k+1}, F_{k+1}\right)-\left(\lambda_{k}^{\mathrm{T}}, \beta_{k}, F_{k}\right)\right\| \leq \varepsilon
$$

where $\varepsilon$ is a user-specified tolerance ( $\varepsilon=0.001$ was used in this study).

\section{Test problems}

Based on the formulation presented, a program (called RigidMethod3D) has been developed for slope stability analysis. Five test examples documented in the literature have been used to validate this method. The potential failure mass is divided 
into a number of columns with vertical interfaces. The Newton method is used to find the safety factor. The initial values of the unknowns are: $F_{0}=10, \beta_{0}=1$, and $\boldsymbol{\lambda}_{0}=\left[\begin{array}{llll}0 & 0 & 0 & 0\end{array}\right]^{\mathrm{T}}$. The results indicate that the Newton method offers rapid convergence and all examples are convergent within, at most, six iteration steps.

\section{Example 1: Fredlund and Krahn (1977)}

The proposed method is firstly validated using a 2-d example taken from Fredlund and Krahn (1977). The example geometry and soil parameters are shown in Fig. 3. The problem was considered in 2-d analysis for two different cases: Case 1 involves a circular failure surface in a homogeneous slope, and Case 2 involves a composite failure surface when the slope contains a weak layer.

For 3-d analysis, the failure surface was extended as a cylinder rotating around an axis parallel to the $x$ axis and the resistance at two ends of the cylinder was ignored. To keep consistence with the width of the discretized slices $(0.3 \mathrm{~m})$ used by Fredlund and Krahn, the size of columns for discretisation of the 3-d failure mass is $0.3 \mathrm{~m} \times 0.3$ $\mathrm{m}$. The solutions are convergent within five iteration steps, although the initial values for $F$ and $\beta$ have been set far from the real solution. The calculated factors of safety and sliding directions for both cases are listed in Table 1. It is interesting to note that the predicted sliding direction agrees well with the direction of the $y$ axis. For comparison, the results from other 2-d rigorous methods are also listed in Table 1. It is evident that the factors of safety obtained using the present and 2-d rigorous methods are in reasonably close agreement.

\section{Example 2: Zhang (1988)}


The example is from Zhang (1988), which is extended from the 2-d profile shown in Fig. 3. The problem was analysed for two different cases: Case 1 involves a failure surface which is circular in the $y-z$ plane and ellipsoidal in the out-of-plane direction (Fig. 4a). In Case 2, the failure surface is composed of an ellipsoidal surface and a weak layer (Fig. 4b).

The proposed method is used to evaluate the factor of safety and the sliding direction of the failure mass. For the two cases, the size of columns for discretisation of the failure mass is $1 \mathrm{~m} \times 1 \mathrm{~m}$ and the total number of columns is 1852 . The calculation results are summarized in Table 2. The solutions are convergent within five iteration steps, and the resulting factors of safety for the two cases are 2.127 and 1.766 , respectively. It is interesting to note that the solution for the sliding direction is 1.57 radians $\left(90^{\circ}\right)$ for the two cases, as would be anticipated for a problem with symmetrical failure surfaces. Chen et al. (2001) studied the example using a strict upper-bound limit analysis approach. For comparison, the values of safety factor from the upper-bound approach are also shown in Table 2. It can be seen that the relative differences between the present and upper-bound methods are within an acceptable range of $6 \%$.

This example has also been re-evaluated by a number of investigators as part of the validation process for their 3 -d limit equilibrium methods. The calculated factors of safety from various methods are listed in Table 3. Among these works in Table 3, the 3-d methods by Zhang (1988), Hungr et al. (1989), Lam and Fredlund (1993) and Chen et al. (2003) belong to the simplified ones which can satisfy at most four 
equilibrium conditions, while the method by Zheng (2012) belongs to the rigorous one which meets all six equilibrium conditions. In both Huang's simplified, and generalised methods, the former only meets two-directional moment equilibrium conditions, while the latter meets three-directional force and two-directional moment equilibrium conditions which is also called quasi-rigorous 3-d method. By comparing the results from various methods listed in Table 3, it was found that, for Case 1 involving a simple ellipsoidal slip surface, the factors of safety obtained using different approaches are in reasonably close agreement. For Case 2 involving the composite slip surface with a weak layer, the values of safety factor from rigorous and quasi-rigorous methods are larger than that from simplified methods. The reason is probably that the above-mentioned simplified methods ignore the horizontal inter-column shear forces along the slip direction. Obviously, the shear forces on the two sides of columns help stabilize the failure mass, especially for the case of weak-plane induced 3-d failure.

To examine the effects of the size of columns on solution accuracy, various numbers of column are used to discretise the failure mass. Fig. 5 shows the factor of safety and sliding direction for different numbers of columns. It can be seen that the safety factor and sliding direction approach their corresponding steady values with increasing numbers of columns, or equivalently, decreasing sizes of columns. This indicates that there is a reasonable trend in the convergence of the solutions using the proposed 3-d method with decreasing column size.

\section{Example 3: Vertical cut slopes}


In this example two vertical cut slopes are considered as shown in Fig. 6. Case 1 involves a failure mass with a known spherical slip surface, which is symmetrical about an axis inclined at $45^{\circ}$ to the $x$-axis (Fig. 6a). The unit weight of the failure mass is $17.64 \mathrm{kN} / \mathrm{m}^{3}$. The failure surface has a cohesion of $24.5 \mathrm{kPa}$ and friction angle of $20^{\circ}$. The potential failure mass is divided into 1840 columns measuring 0.1 $\mathrm{m} \times 0.1 \mathrm{~m}$. Using the proposed 3-d method, we have obtained a safety factor of 1.848 and a sliding direction of 0.77 radians $\left(44^{\circ}\right)$. The calculated sliding direction agrees well with the direction of the symmetrical axis. This case is also analysed by a number of investigators to validate their $3-\mathrm{d}$ methods of analysis. Huang and Tsai (2000) have obtained a factor of safety of 1.766 using Bishop's method, whereas Cheng and Yip (2007) have obtained 1.801 and 1.803 for Bishop's, and the Morgenstern-Price, methods. The factor of safety resulting from the present study is comparable to those obtained by Huang and Tsai (2000) and Chen and Yip (2007).

Case 2 in this example, from Cheng and Yip (2007), involves an asymmetric rigid block failure (Fig. 6b), which has a unit weight of $20 \mathrm{kN} / \mathrm{m}^{3}$. The shear strength parameters of the failure surface are friction angle $\phi=32^{\circ}$ and cohesion $c=0$. The safety factor and sliding direction (rotating counterclockwise from the $x$-axis) can be determined explicitly as 0.280 and $117^{\circ}$. A total of 1482 columns measuring $0.05 \mathrm{~m} \times$ $0.05 \mathrm{~m}$ are used to discretise the rigid block. Using the proposed 3-d method, we have obtained a safety factor of 0.279 and a sliding direction of $2.034\left(117^{\circ}\right)$. To examine the effects of column size on the precision of our solutions, various column sizes are adopted for analysis. Fig. 7 shows the variation of the calculated factors of safety and 
sliding directions with column size. For case 2, it can be seen that the column size has nearly no influence upon the precision of the solutions. For the simple block failure mode, the resulting safety factor and sliding direction have a high precision when a total number of six columns measuring $0.5 \mathrm{~m} \times 0.5 \mathrm{~m}$ are used to discretise the failure mass.

For the two slopes in this example, one rotational failure and the other a translational failure, the sliding directions for both cases are correctly predicted by the proposed method. This further demonstrates the ability of the proposed rigorous method to predict the direction of sliding, which is very useful for the design of slope support schemes.

\section{Example 4: Wedge failure analysis}

Wedge failure is a frequently encountered instability phenomenon in rock slope engineering (Jiang et al. 2013). The wedge method proposed by Hoek and Bray in their classic textbook Rock Slope Engineering (Third Edition 1981) is widely applied in slope stability analysis. The traditional method only meets force equilibrium conditions and the sliding direction is usually assumed to be parallel to the line of intersection of two discontinuity planes. The 3-d method presented in this study remove the limitations of the traditional method and can determine the safety factor and sliding direction of wedges.

Two typical wedges, one symmetrical, and the other asymmetrical, have been analysed using the proposed 3-d method. Orientations and strength parameters of discontinuity planes forming the wedges are listed in Table 4 . The size of columns for 
discretisation of the wedges is set to $3 \mathrm{~m} \times 3 \mathrm{~m}$. As shown in Fig. 8, the symmetrical wedge is divided into 1410 columns and the asymmetrical wedge is divided into 1270 columns. The calculated factors of safety and sliding directions for the two wedges are listed in Table 5. For comparison, the analytical results from the traditional Hoek-Bray method are also listed in Table 5. It is evident that for both the symmetrical and asymmetrical wedges, the proposed 3-d method gives satisfactory results for the prediction of both safety factors and sliding directions.

To investigate the effects of column size on solution accuracy, ten different column sizes are adopted for analysis. Assuming the analytical results from the traditional method are the exact solution, for different column sizes, Fig. 9 shows the relative error for different column sizes. There is a general trend in which the relative error decreases with decreasing column size, or equivalently, increasing numbers of columns. For the two wedges in this example, the proposed 3-d method has sufficient precision even if the total number of columns used in the discretisation of the failure mass is relatively small.

\section{Example 5: Michalowski (2010)}

The example is taken from Michalowski (2010). A uniform 1:1 slope is built of overconsolidated soil with a friction angle of $20^{\circ}$, cohesion of $20 \mathrm{kPa}$, and unit weight of $18 \mathrm{kN} / \mathrm{m}^{3}$. The height of the slope is $15 \mathrm{~m}$, and its width is restrained to 30 $\mathrm{m}$ by rock formations. The stability analysis of the slope involves a search for the slip surface with the minimum factor of safety. According to the failure mechanism of homogeneous slopes (Leshchinsky and Baker 1986, Michalowski 2010, Zhang et al. 
2016), candidate slip surfaces are constructed using a central cylinder and two caps attached to it at both ends in this study. The equations for the composite slip surface can be expressed as

$$
\left\{\begin{array}{lr}
\frac{\left[x-\left(x_{0}-l / 2\right)\right]^{2}}{R_{x}^{2}}+\frac{\left(y-y_{0}\right)^{2}}{R_{y}^{2}}+\frac{\left(z-z_{0}\right)^{2}}{R_{z}^{2}}=1 & \left(x \leq x_{0}-l / 2\right) \\
\frac{\left(y-y_{0}\right)^{2}}{R_{y}^{2}}+\frac{\left(z-z_{0}\right)^{2}}{R_{z}^{2}}=1 & \left(x_{0}-l / 2 \leq x \leq x_{0}+l / 2\right) \\
\frac{\left[x-\left(x_{0}+l / 2\right)\right]^{2}}{R_{x}^{2}}+\frac{\left(y-y_{0}\right)^{2}}{R_{y}^{2}}+\frac{\left(z-z_{0}\right)^{2}}{R_{z}^{2}}=1 & \left(x \geq x_{0}+l / 2\right)
\end{array}\right.
$$

where $\left(x_{0}, y_{0}, z_{0}\right)$ is the coordinates of the centre of the composite surface. $R_{x}, R_{y}, R_{z}$ are the semi-radiuses of the ellipsoid, respectively, and $l$ is the length of the elliptic cylindrical which is inserted between the left and right half ellipsoid.

Once the candidate slip surfaces are constructed, an optimization algorithm can be applied to search for the critical slip surface. For the homogeneous slope involved in Example 5, the critical slip surface found by the proposed method is shown in Fig. 10. The centre's coordinates $\left(x_{0}, y_{0}, z_{0}\right)$ in Eq. (32) for the critical composite slip surface are $(15.0,7.6,35.1)$ while $R_{x}, R_{y}, R_{z}, l$ are $17.5,17.5,30.1$ and $8.3 \mathrm{~m}$, respectively. The minimum factor of safety corresponding to the critical slip surface is 1.193, which is in close agreement with 1.18 obtained by Michalowski (2010) using his upper-bound approach. The sliding direction of the critical failure mass is determined as 1.572 radians $\left(90^{\circ}\right)$, which is consistent with the anticipated sliding direction of the uniform slope. 


\section{Discussion}

\section{Conditions of physical admissibility}

In the framework of limit equilibrium theory, assumptions need to be introduced to make the problem statically determinate. For 2-d analysis, as pointed out by Chen and Morgenstern (1983), a solution based on assumed inter-slice forces should satisfy the physical admissibility conditions. These require that the normal stress along the failure surface, and the horizontal thrust between slices, must be compressive. In 3-d analysis the problem of physical admissibility was less often addressed in the past. For the proposed 3-d method, since the internal forces acting on the column-interfaces are not able to be fully resolved, only the condition under which there is no tension over the failure surface is considered.

Once the system (21) is solved, the normal stress acting on the failure surface could be computed using Eq. (13). The distributions of normal stresses over the failure surfaces for both cases in Example 1 are plotted in Figs 11a and 11b, respectively. It can be seen that the normal stresses are positive and meet the admissibility condition. For comparison, the normal stresses obtain by Spencer's method (using Slide software) are also shown in Fig. 11. Overall, the normal stress distributions from the two different methods are nearly identical. It is noticed that negative normal tresses occur at the top of the failure mass in the Slide analysis. For both cases in Example 1, it appears that the normal stresses produced by the proposed method are more reasonable.

The distributions of normal stresses over the failure surfaces for the two cases in 
Example 2 are plotted in Figs 12a and 12b, respectively. It can be seen that the normal stresses are positive and meet the admissibility condition. Since the cases in this example are characterised by symmetry of their failure masses, the distributions of normal stresses are also quasi-symmetrical.

Figs $13 \mathrm{a}$ and $13 \mathrm{~b}$ show the distributions of normal stresses over the failure surfaces for the two cases in Example 3. It was found that negative normal stresses exist between the upper columns near the two corners of the top of the failure mass. For this kind of failure mass, with a steep slip surface at the top of the slope, similar phenomena also occur in 2-d analysis (Leshchinsky 1990; Zheng and Tham 2009). A treatment designed to avoid such negative normal stresses involves formation of a tension crack at the crest of the slope; but this is beyond the scope of this present study. Overall, the resulting normal stresses for the two vertical slopes in Example 3 appear to be acceptable because only a small part near the corners of the failure mass experience tensile stresses.

Figs $14 \mathrm{a}$ and $14 \mathrm{~b}$ show contours of normal stresses for the two cases in Example 4. It can be seen that the normal stresses are positive and satisfy the physical admissibility condition on all slip surfaces. For the symmetrical wedge, the distribution of normal stresses was quasi-symmetrical, which indicates that the results are reasonable. For the asymmetrical wedge, the discontinuity in, and the local concentration of, normal stresses occur along the line of intersection of the left and right failure planes.

Convergence of solutions 
In general, the global equilibrium equations for slope stability analysis are highly non-linear. The Newton method is the most commonly-used iteration procedure for solving the global equations: although it is successful and efficient in most cases, the method usually requires that initial iteration values are close enough to the real solution. Even for 2-d analysis, as noted by Zheng and Tham (2009), the convergence range of the Newton method for rigorous slice methods is very narrow. Furthermore, there are also some examples where convergence for the rigorous slice methods cannot be achieved thereby (Duncan 1996; Cheng et al. 2008).

To examine the numerical performance of the Newton method for the proposed 3 - $d$ rigorous method, the initial iteration values of the factor of safety are set to be very far from the real solution. Letting $F_{0}=100, \beta_{0}=1$, and $\lambda_{0}=\left[\begin{array}{llll}0 & 0 & 0 & 0\end{array}\right]^{\mathrm{T}}$, all eight cases in the first four examples are used for analysis. Figs 15a and 15b show the iteration process of the calculated factor of safety and direction of sliding, respectively. Although the initial iteration values are far from the real solutions, the calculation results for the eight cases are convergent within at most six iteration steps. Figs $16 \mathrm{a}$ and $16 \mathrm{~b}$ show the changes in unbalanced force and moment with each iteration step, respectively. It can be seen that the unbalanced force and moment decrease rapidly and are less than $10^{-5}$ by the end of convergence.

\section{Engineering applications}

Landfill Unit B-19 forms part of a Class I hazardous-waste treatment-and-storage facility at Kettleman City, California (Mitchell et al. 1990). The landfill area is a large 
oval-shaped bowl carved into an existing valley, which has a nearly flat central base (inclined at a $2 \%$ grade), and side slopes of 1 in 2 , or 1 in 3 . The sides and base of the landfill were lined with a multi-layer liner system to prevent the escape of hazardous materials. Phase I-A, covering an area of about 15 acres (6 ha), comprises the northern portion of Unit B-19 of the facility. A plan view of the Unit B-19, Phase I-A landfill is shown in Fig. 17. On Saturday, 19 March, 1988, a slope-stability failure occurred that resulted in lateral surface displacements of the waste fill of up to 35 feet $(10.7 \mathrm{~m})$ and vertical surface settlements of the fill of up to 14 feet $(4.3 \mathrm{~m})$ (Mitchell et al. 1990). Based on on-site observations and survey records, the slip surface was found to be located at the interface of the underlying liner system.

Analyses of the Kettleman Hills waste landfill slope failure have been carried out by a number of investigators since the failure (Seed et al. 1990; Byrne et al. 1992; Gilbert et al. 1998; Filz et al. 2001; Chang 2005; Zheng 2009). In this study, the proposed method is used to evaluate the stability of the pre-slide Kettleman landfill slope. Based on the pre-slide topography of the ground surface, and the sliding surface of the waste landfill, a 3-d calculation model was established for subsequent stability analysis, as shown in Fig. 18. A total of 1223 columns measuring $5 \mathrm{~m} \times 5 \mathrm{~m}$ are used to discretise the sliding mass. The waste fill is assumed to have an average bulk unit weight of $17.3 \mathrm{kN} / \mathrm{m}^{3}$. The selection of the strengths of the sliding surface materials within the landfill liner system is very important for the stability assessment of such a landfill slope. In view of the large sliding distance occurring in the field, the torsional-ring-shear apparatus appears to provide the best estimate of field peak, and 
residual interface, shear strengths (Stark and Poeppel 1994; Chang 2005). Based on the torsional-ring-shear test results from Stark and Poeppel, a residual interface strength $\left(\varphi_{r}=5.9^{\circ}\right)$ is adopted for the landfill side-slopes and a peak interface strength $\left(\varphi_{p}=8.3^{\circ}\right)$ is adopted for the landfill base in this present study. Using the proposed 3-d method, we have obtained a safety factor of 1.036 and a sliding direction of $1.797\left(\mathrm{~S} 57^{\circ} \mathrm{E}\right)$ for the landfill slope in its pre-slide geometry. The factor of safety is slightly more than unity, indicating that the Phase I-A landfill was marginally stable: this matched field observations before failure. This case was also analysed by Stark and Poeppel (1994) using identical interface strength parameters. They obtained a factor of safety of 0.92 based on Janbu's method (1973), which is less than that arising from the proposed method. Possible reasons for Janbu's method yielding a lower factor of safety are that Janbu's method neglects the vertical component of inter-slice-shear forces and only satisfies overall vertical and horizontal force equilibrium conditions.

From Seed et al. (1990), Fig. 19 shows on-site measurements of horizontal displacement vectors of the landfill slope. The resulting calculated direction of slide from the proposed method is also shown in Fig. 19. It is interesting to note that the direction of slide is in good agreement with the actual observed sliding direction. Fig. 20 shows the distributions of the resulting normal stresses along the sliding surface. It can be seen that the normal stresses are positive and satisfy the admissibility condition, which indicates that the solutions from the proposed method are both reasonable and acceptable. In addition, it can be seen from Fig. 20 that the 
normal stress acting on the base of the waste landfill ranged from 400 to $480 \mathrm{kPa}$. This is in good agreement with the research into the normal stress at the time of failure by Stark and Poeppel (1994).

\section{Conclusions}

Most slope failures exhibit remarkable asymmetrical variation in the out-of-plane direction. In this study, a rigorous method for 3-d asymmetrical slope stability analysis is proposed based on an assumed distribution of normal stress on the slip surface. The method is validated by using five typical examples documented in the literature. The failure of the Kettleman waste landfill slope is also re-evaluated using the proposed method. The calculated stability and direction of sliding match field observations. Based on this work, the following key conclusions can be drawn:

(1) The proposed method is strict in that it meets both three force-equilibrium, and three moment-equilibrium conditions. Compared with most existing 3-d methods only considering partial equilibrium conditions, our method is more rigorous and accurate.

(2) Since the limitation in predefining a symmetrical plane or sliding direction in 3-d stability analysis is removed, the present method can accommodate asymmetrical slip surfaces. It is therefore applicable to a wide range of practical problems.

(3) The proposed method can not only calculate the factor of safety, but also accurately predict the direction of sliding of the potential failure mass. This provides a new insight for the design optimisation of slope reinforcement where the optimal 
trend of bolting forces is in a direction opposite to that of the sliding direction of the failure mass.

(4) The Newton iteration procedure, as used in the proposed method, has a large range of convergence and a fast convergence rate. The calculation results for all of the examples used in this study are convergent within six iteration steps, although the initial iteration values are chosen so as to be far from the real solutions.

(5) Similar to a 2-d analysis, the proposed method will achieve sufficient approximation precision with an increasing number of discretised columns, or equivalently, decreasing sizes of columns. It is interesting to note that, for a single-plane sliding mode (Case 2, Example 3), the size of the columns used has nearly no influence upon the precision of the solutions.

(6) The proposed method considers the physical admissibility condition on the slip surface. It is noteworthy that local tensile stresses may occur for this kind of failure mass with a steep slip surface at the top of some slopes.

\section{Acknowledgements}

The work reported in this paper has received financial support from the National Natural Science Foundation of China (Nos. 51679173) and Natural Science Foundation of Hubei Province (No. 2016CFA083). This support is gratefully acknowledged. 


\section{References}

Baker, R., and Leshchinsky, D. 1987. Stability analysis of conical heaps. Soils Found., 27(4): 99-110.

Byrne, J.R., Kendall, J., and Brown, S. 1992. Cause and mechanism of failure of Kettleman Hills landfill B-19, Phase IA. Stability and Performance of Slopes and Embankments, New York, Vol. 2, 1188-1215.

Chang, M. 2005. Three-dimensional stability analysis of the Kettleman Hills landfill slope failure based on observed sliding-block mechanism. Computers and Geotechnics, 32: 587-599.

Chen, Z.Y., and Morgenstern, N.R. 1983. Extensions to the generalized method of slices for stability analysis. Can. Geotech. J., 20: 104-109.

Chen, R.H., and Chameau, J.L. 1982. Three-dimensional limit equilibrium analysis of slopes. Géotechnique, 33(1): 31-40.

Chen, Z.Y., Mi, H.L., Zhang, F.M., and Wang, X.G. 2003. A simplified method for 3D slope stability analysis. Canadian Geotechnical Journal, 40: 675-683.

Chen, Z.Y., Wang, X.G., Haberfield, C., Yin, J.H., and Wang, Y.J. 2001. A three-dimensional slope stability analysis method using the upper bound theorem Part I: theory and methods. International Journal of rock mechanics and mining sciences, 38: 369-378.

Cheng, Y.M., Lansivaara, T., and Siu, J. 2008. Impact of convergence on slope stability analysis and design. Computers and Geotechnics, 35: 105-113.

Cheng, Y.M., and Yip, C.J. 2007. Three-Dimensional asymmetrical slope stability 
analysis extension of Bishop's, Janbu's, and Morgenstern-Price's techniques. J. Geotech. and Geoenviron. Engng, ASCE, 133(12): 1544-1555.

Duncan, J.M. 1996. State of the art: limit equilibrium and finite element analysis of slopes. J. Geotech. and Geoenviron. Engng, ASCE, 122(7): 577-596.

Filz, G.M., Esterhuizen, J.J.B., and Duncan, J.M. 2001. Progressive failure of lined waste impoundments. J. Geotech. and Geoenviron. Engng, ASCE, 127(10): 841-848.

Fredlund, D.G.., and Krahn, J. 1977. Comparison of slope stability methods of analysis. Can. Geotech. J., 14: 429-439.

Gilbert, R.B., Wright, S.G., and Liedtke, E. 1998. Uncertainty in back analysis of slope: Kettleman Hills case history. J. Geotech. and Geoenviron. Engng, ASCE, 124(12): 1167-1176.

Griffiths, D.V., and Marquez, R.M. 2007. Three-dimensional slope stability analysis by elasto-plastic finite elements. Géotechnique, 57(6): 537-546.

Hoek, E.T., and Bray, J.W. 1981. Rock slope engineering, 3rd edn. Inst. Mining and Metallurgy, London, UK.

Huang, C.C., and Tsai, C.C. 2000. New Method for 3D and asymmetrical slope stability analysis. J. Geotech. and Geoenviron. Engng, ASCE, 126(10): 917-927.

Huang, C.C., Tsai, C.C., and Chen, Y.H. 2002. Generalized method for three-dimensional slope stability analysis. J. Geotech. and Geoenviron. Engng, ASCE, 128(10): 836-848.

Hungr, O., Slgado, F.M., and Byrne, P.M. 1989. Evaluation of a three-dimensional method of slope stability analysis. Canadian Geotechnical Journal, 26: 679-686. 
Janbu, N. 1973. Slope stability computations. Embankment dam engineering: casagrande volume. John Wiley and Sons, New York, 47-86.

Jiang, Q.H., Liu, X.H., Wei, W., and Zhou, C.B. 2013. A new method for analyzing the stability of rock wedges. Int. J. Rock Mech. Min. Sci., 60: 413-422.

Kalatehjari, R., Arefnia, A., Rashid, A.S.A, Ali, N., and Hajihassani M. 2015. Determination of three-dimensional shape of failure in soil slopes. Can. Geotech. J., 52: $1283-1301$.

Lam, L., and Fredlund, D.G. 1993. A general limit equilibrium model for three-dimensional slope stability analysis. Canadian Geotechnical Journal, 30: 905-919.

Leshchinsky, D. 1990. Slope stability analysis: generalized approach. Journal of Geotechnical Engineering, 116(15): 851-867.

Leshchinsky, D., and Baker, R. 1986. Three-dimensional slope stability: End effects. Soils and Found., 26(4): 98-110.

Leshchinsky, D., and Huang, C.C. 1992. Generalized three-dimensional slope stability analysis. Journal of Geotechnical Engineering, ASCE, 118(11), 1748-1764.

Michalowski, R. L. 2010. Limit analysis and stability charts for 3D slope failures. Journal of Geotechnical and Geoenvironmental Engineering, ASCE, 136(4): 583-593.

Mitchell, J.K., Seed, R. B., and Seed, H.B. 1990. Kettleman Hills waste landfill slope failure. I: liner system properties. J. Geotech. Engrg., ASCE, 116(4): 647-668.

Roohollah, K., Ahmad, S.A.R., Mohsen, H., Mehrdad, K., and Nazri, A. 2014. 
Determining the unique direction of sliding in three-dimensional slope stability analysis. Engineering Geology, 182: 97-108.

Sarma, S.K., and Tan, D. 2006. Determination of critical slip surface in slope analysis. Géotechnique, 56(8): 539-550

Seed, R.B., Mitchell, J. K., and Seed, H.B. 1990. Kettleman Hills waste landfill slope failure. II: stability analyses. J. Geotech. Engrg., ASCE, 116(4): 669-690.

Stark, T.D., and Poeppel, A.R. 1994. Landfill liner interface strengths from torsional-ring-shear tests. J. Geotech. Engrg., ASCE, 120(3): 597-615.

Sun, G.H., Zheng, H., and Jiang, W. 2012. A global procedure for evaluating stability of three-dimensional slopes. Nat. Hazards., 61: 1083-1098.

Yamagami, T., and Jiang, J.C. 1996. Determination of the sliding direction in three-dimensional slope stability analysis. Proc. 2nd Int. Conf. on soft soil Engineering, Nanjing, China, Vol. 1, 567-572.

Yamagami, T., and Jiang, J. C. 1997. A search for the critical slip surface in three-dimensional slope stability analysis. Soils and Found., 37(3): 1-16.

Zhang, F., Leshchinsky, D., Baker, R., Gao, Y., and Leshchinsky, B. 2016. Implications of variationally derived 3D failure mechanism. Int. J. Numer. Anal. Meth. Geomech., 40(18): 2514-2531.

Zhang, X. 1988. Three-dimensional stability analysis of concave slopes in plan view. Journal of Geotechnical Engineering, ASCE, 114(6): 658-671.

Zheng, H. 2009. Eigenvalue Problem from the Stability Analysis of Slopes. J. Geotech. and Geoenviron. Engng, ASCE, 135(5): 647-656. 
Zheng, H. 2012. A three-dimensional rigorous method for stability analysis of landslides. Engineering Geology 145-146: 30-40.

Zheng, H., and Tham, L.G. 2009. Improved Bell's method for the stability analysis of slopes. Int. J. Numer. Anal. Meth. Geomech., 33: 1673-1689.

Zhou, X.P., and Cheng H. 2013. Analysis of stability of three-dimensional slopes using the rigorous limit equilibrium method. Engineering Geology, 160: 21-33.

\section{Figure captions}

Fig. 1. (a) A failure mass $\Omega$ with an asymmetrical slip surface $S$; (b) a plan view of the divided columns and slip surface.

Fig. 2. (a) Forces acting on a column; (b) relationship between the unit vector of the mobilised shear force and its projection on the $x-y$ plane.

Fig. 3. Slope profile used in Example 1.

Fig. 4. Discretisation of the failure mass: (a) with an ellipsoidal failure surface; (b) with a composite failure surface containing a weak plane.

Fig. 5. Variation of calculated factors of safety and directions of sliding with the number of columns: (a) Case 1, Example 2; (b) Case 2, Example 2.

Fig. 6. Slope geometry for Example 3: (a) involving a symmetrical rotation failure; (b) involving an asymmetrical rigid block failure.

Fig. 7. Variation of calculated factors of safety and directions of sliding with column size: (a) Case 1, Example 3; (b) Case 2, Example 3.

Fig. 8. The failure mass is divided into columns: (a) symmetrical wedge failure; (b) asymmetrical wedge failure.

Fig. 9. Variation of relative errors in safety factor and sliding direction with the number of columns: (a) Case 1, Example 4; (b) Case 2, Example 4.

Fig. 10. Slip surface with the minimum factor of safety for Example 5.

Fig. 11. Comparison of normal stresses distributions over the failure surfaces: (a) Case 1, Example 1; (b) Case 2, Example 1.

Fig. 12. Distributions of normal stresses over the failure surfaces: (a) Case 1, Example 
2; (b) Case 2, Example 2.

Fig. 13. Distributions of normal stresses over the failure surfaces: (a) Case 1, Example 3; (b) Case 2, Example 3.

Fig. 14. Contours of normal stresses over the failure surfaces: (a) Case 1, Example 4; (b) Case 2, Example 4.

Fig. 15. (a) Calculated factor of safety versus iteration step number; (b) Calculated direction of sliding versus iteration step number.

Fig. 16. (a) Calculated unbalanced force versus iteration step number; (b) Calculated unbalanced moment versus iteration step number.

Fig. 17. Plan view of Unit B-19, Phase I-A landfill.

Fig. 18. 3-d model and the division of columns in the chosen waste landfill slope.

Fig. 19. Calculated direction of sliding and horizontal displacement vectors of the chosen landfill slope.

Fig. 20. Normal stresses over the failure surfaces: (a) 3-d view; (b) plan view. 


\section{Captions of tables}

Table 1. Results for two different cases in Example 1.

Table 2. Results for two different cases in Example 2.

Table 3. Comparison of the factors of safety from various methods.

Table 4. Orientation of discontinuity planes forming wedges.

Table 5. Results for symmetric and asymmetric wedges in Example 4. 
Table 1. Results for two different cases in Example 1

\begin{tabular}{|c|c|c|c|c|c|}
\hline & \multicolumn{2}{|c|}{ Present study } & \multirow{2}{*}{$\begin{array}{c}\begin{array}{c}\text { Fredlund and } \\
\text { Krahn }\end{array} \\
\text { Factor of Safety }\end{array}$} & \multirow{2}{*}{$\begin{array}{c}\begin{array}{c}\text { Leshchinsky } \\
\text { and Huang }\end{array} \\
\text { Factor of Safety }\end{array}$} & \multirow{2}{*}{$\begin{array}{c}\text { Slide } \\
\text { Software }^{\mathrm{b}}\end{array}$} \\
\hline & Factor of Safety & Direction of sliding & & & \\
\hline Case 1 & 2.089 & 1.571 & 2.073 & 2.080 & 2.101 \\
\hline Case 2 & 1.307 & 1.571 & 1.373 & 1.312 & 1.339 \\
\hline
\end{tabular}

Note: a -Spencer's method; b-Spencer's method in Slide software (Rocscience Int.).

Table 2. Results for two different cases in Example 2

\begin{tabular}{ccccc}
\hline & & Present study $^{\mathrm{a}}$ & $\begin{array}{c}\text { Upper-bound } \\
\text { approach }\end{array}$ \\
\cline { 2 - 5 } & Factor of Safety & Direction of sliding & Iteration times & Factor of Safety \\
\hline Case 1 & 2.127 & $90^{\circ}$ & 5 & 2.262 \\
Case 2 & 1.766 & $90^{\circ}$ & 5 & 1.717 \\
\hline
\end{tabular}

Note: a-Total column number $=1852($ Column size: $1 \mathrm{~m} \times 1 \mathrm{~m})$; b-Reported by Chen et al. $(2001)$.

Table 3. Comparison of the factors of safety from various limit equilibrium methods

\begin{tabular}{cccccccc}
\hline Method & $\begin{array}{c}\text { Zhang } \\
(1988)\end{array}$ & $\begin{array}{c}\text { Hungr et al. } \\
(1989)\end{array}$ & $\begin{array}{c}\text { Lam and } \\
\text { Fredlund (1993) }\end{array}$ & $\begin{array}{c}\text { Huang et al. } \\
(2002)\end{array}$ & $\begin{array}{c}\text { Chen et al. } \\
(2003)\end{array}$ & $\begin{array}{c}\text { Zheng } \\
(2012)\end{array}$ & $\begin{array}{c}\text { Present } \\
\text { study }\end{array}$ \\
\hline Case 1 & 2.122 & 2.167 & - & 2.215 & 2.187 & - & 2.127 \\
Case 2 & 1.553 & 1.620 & 1.603 & $1.645^{\mathrm{s}} / 1.757^{\mathrm{g}}$ & 1.640 & 1.735 & 1.766 \\
\hline
\end{tabular}

Note: s-Simplified method by Huang et al. (2002); g- generalised method by Huang et al. (2002). 
Table 4. Orientation of discontinuity planes forming wedges

\begin{tabular}{llllll}
\hline & Surface & $\begin{array}{l}\text { Dip } \\
(\text { degrees })\end{array}$ & $\begin{array}{l}\text { Dip direction } \\
(\text { degrees })\end{array}$ & $\begin{array}{l}\text { Friction angle } \\
(\text { degrees })\end{array}$ & $\begin{array}{l}\text { Cohesion } \\
(\mathrm{kPa})\end{array}$ \\
\hline $\begin{array}{l}\text { Symmetric } \\
\text { wedge }\end{array}$ & Left failure plane & 45 & 115 & 20 & 20 \\
& Right failure plane & 45 & 245 & 20 & 20 \\
& Slope face & 60 & 180 & Height of wedge $=64.89 \mathrm{~m}$ \\
& Upper surface & 10 & 180 & & 50 \\
\hline Asymmetric & Left failure plane & 40 & 120 & 30 & 50 \\
wedge & Right failure plane & 60 & 240 & 30 & Height of wedge $=100 \mathrm{~m}$ \\
& Slope face & 60 & 180 & & \\
& Upper surface & 0 & 180 & &
\end{tabular}

Note: Unit weight of rock $=26 \mathrm{kN} / \mathrm{m}^{3}$

Table 5. Results for symmetric and asymmetric wedges in Example 4

\begin{tabular}{llllll}
\hline & \multicolumn{2}{l}{ Symmetric wedge } & & \multicolumn{2}{l}{ Asymmetric wedge } \\
\cline { 2 - 3 } \cline { 5 - 6 } \cline { 5 - 6 } The proposed method & 1.275 & $90^{\circ}$ & 1.629 & $104^{\circ}$ \\
The Hoek-Bray method & 1.293 & $90^{\circ}$ & 1.640 & $101^{\circ}$ \\
\hline
\end{tabular}

Note: Total column number for symmetric wedge $=1410$; Total column number for asymmetric wedge $=1270$. 


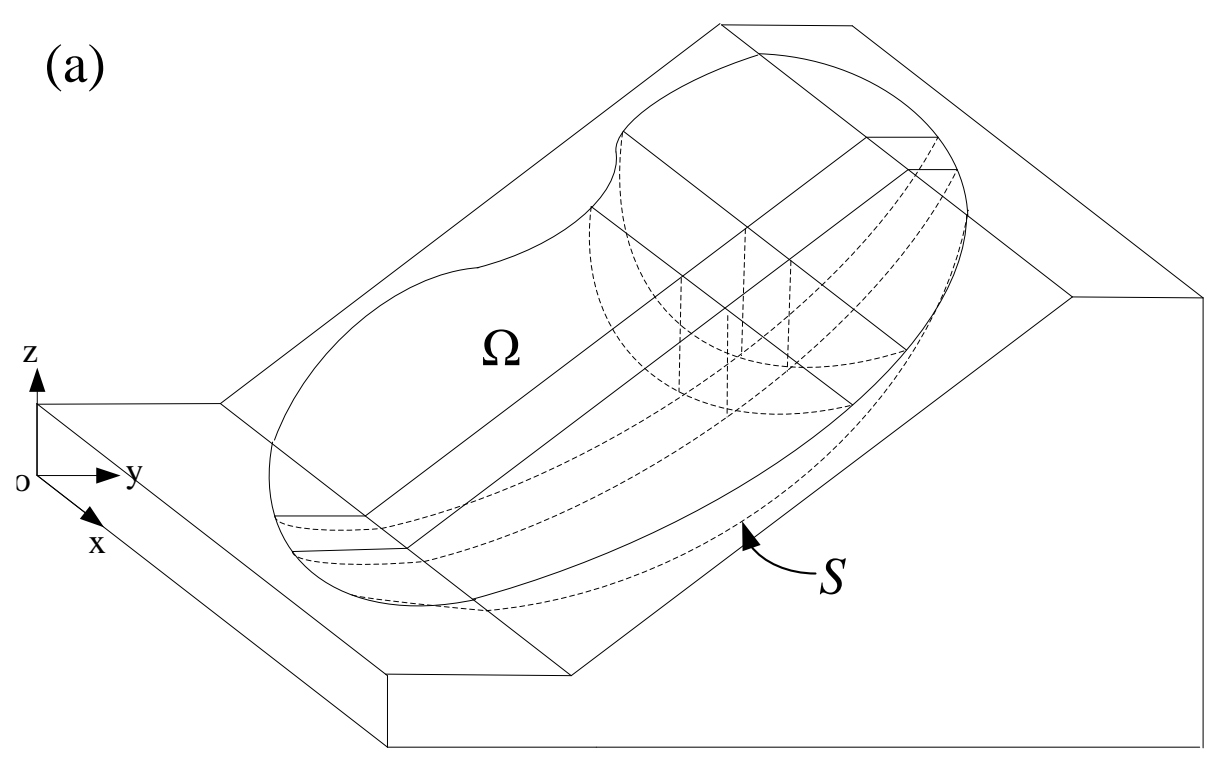

(b)

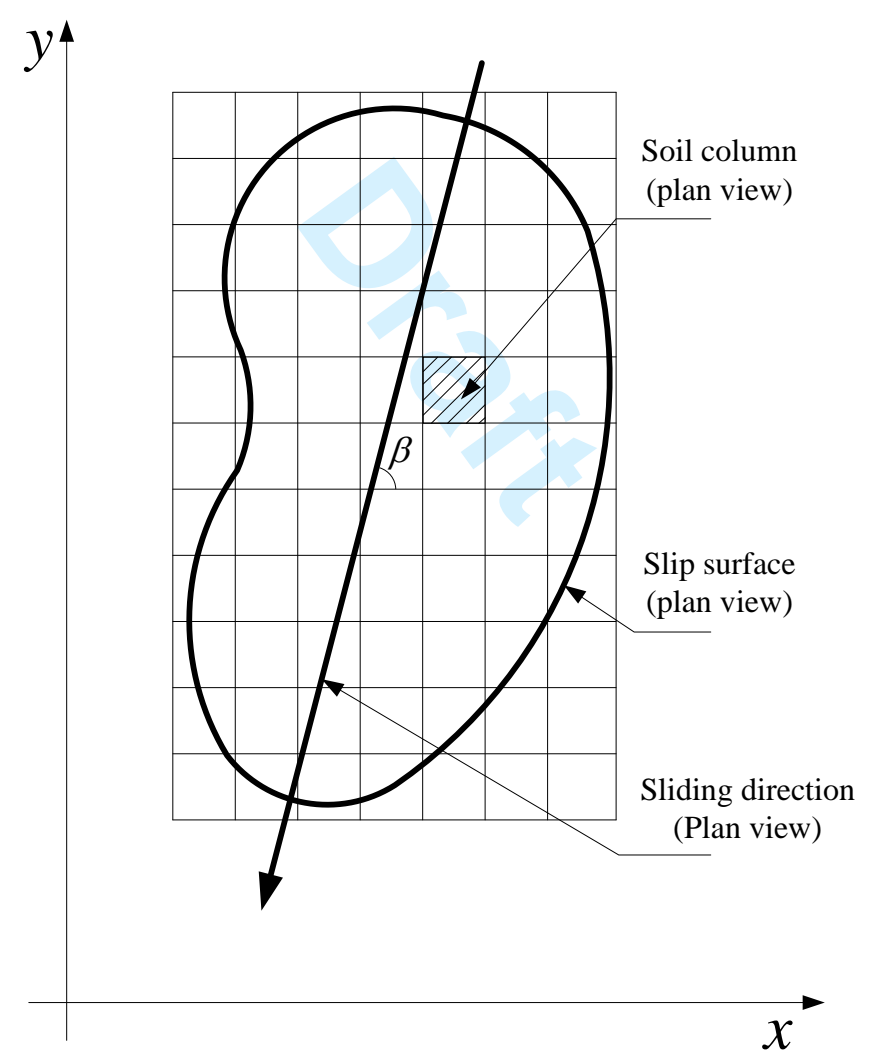

Fig. 1. (a) A failure mass $\Omega$ with an asymmetrical slip surface $S$; (b) a plan view of the divided columns and slip surface. 
(a)

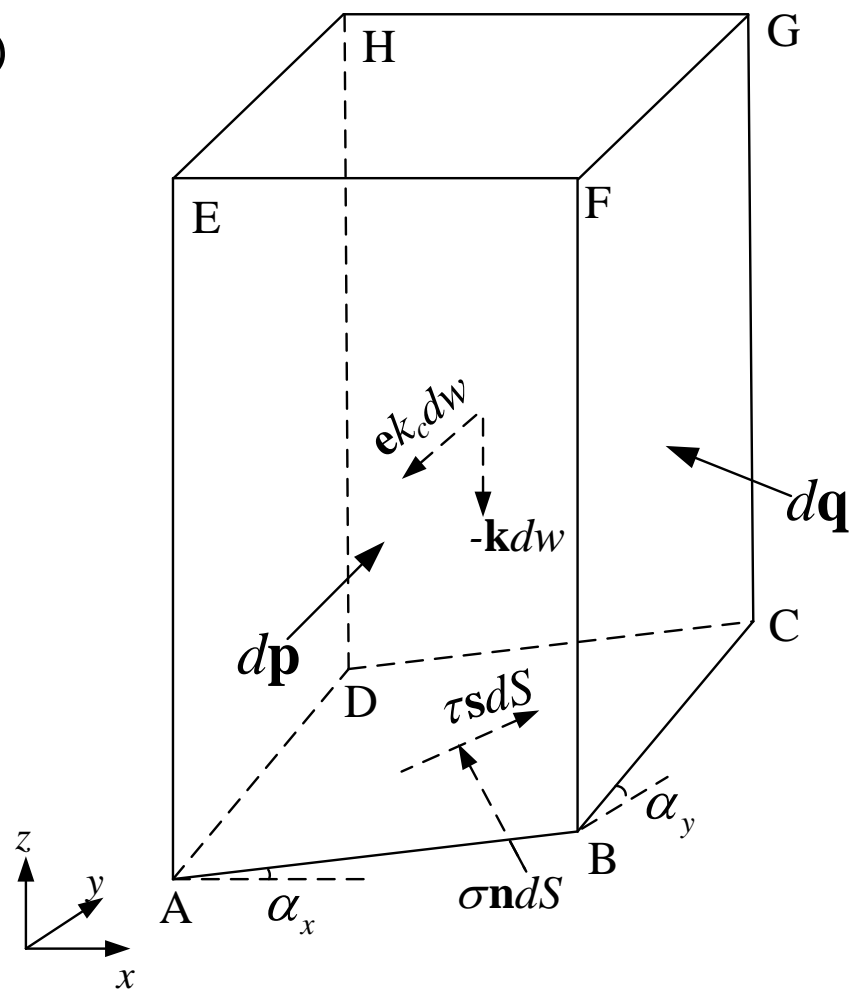

(b)

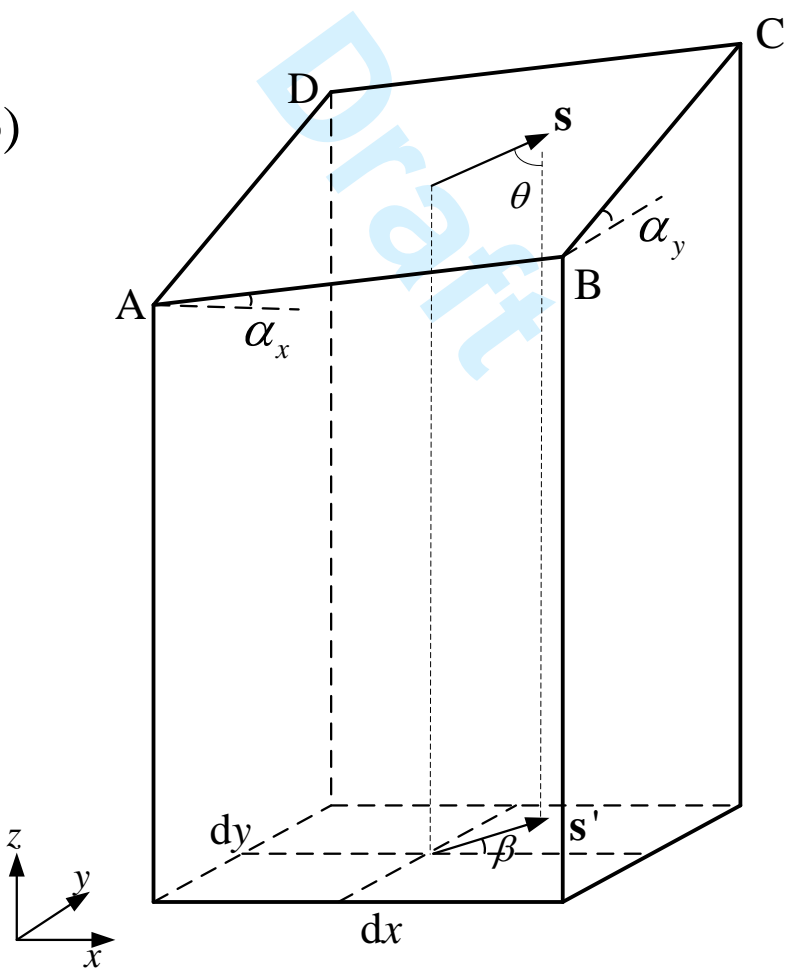

Fig. 2. (a) Forces acting on a column; (b) relationship between the unit vector of the mobilised shear force and its projection on the $x-y$ plane. 


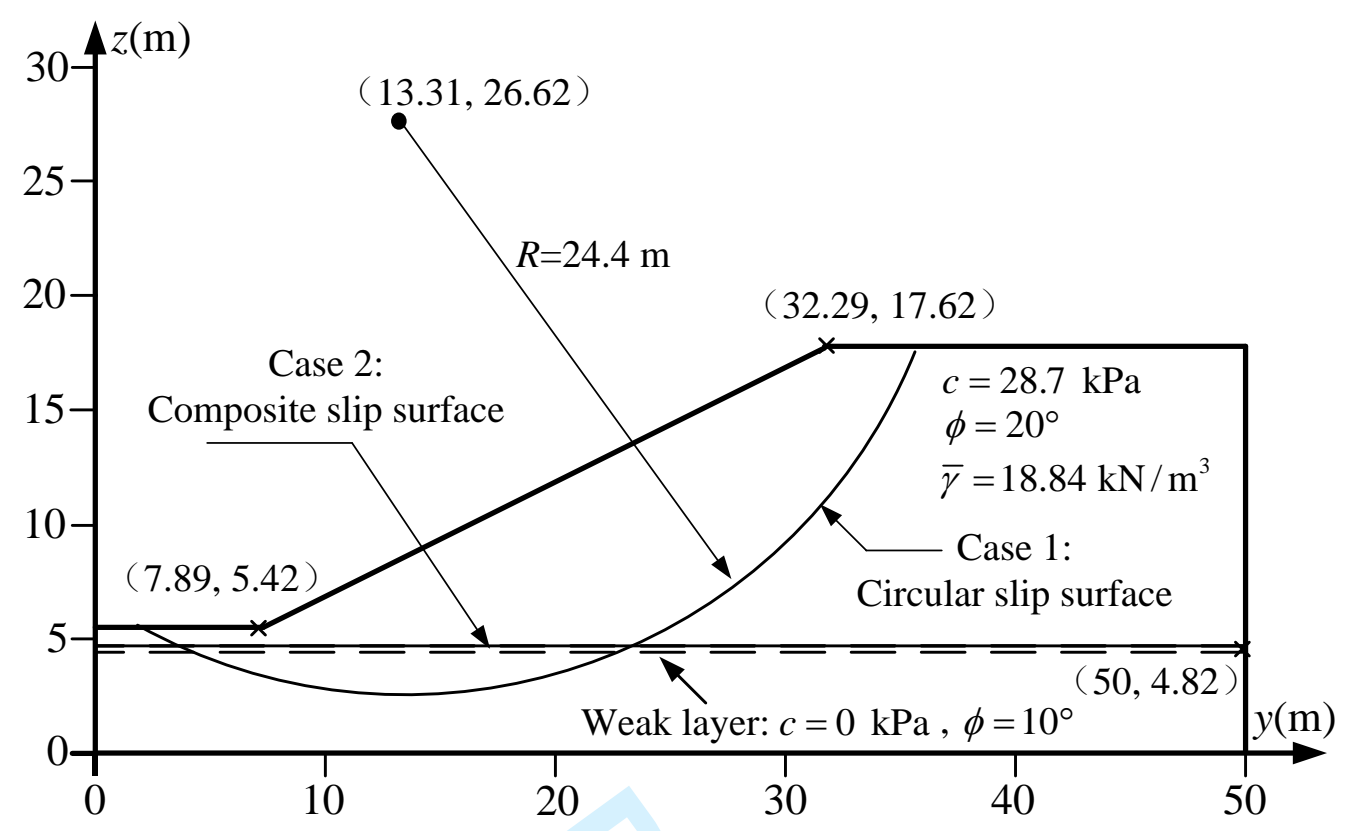

Fig. 3. Slope profile used in Example 1. 

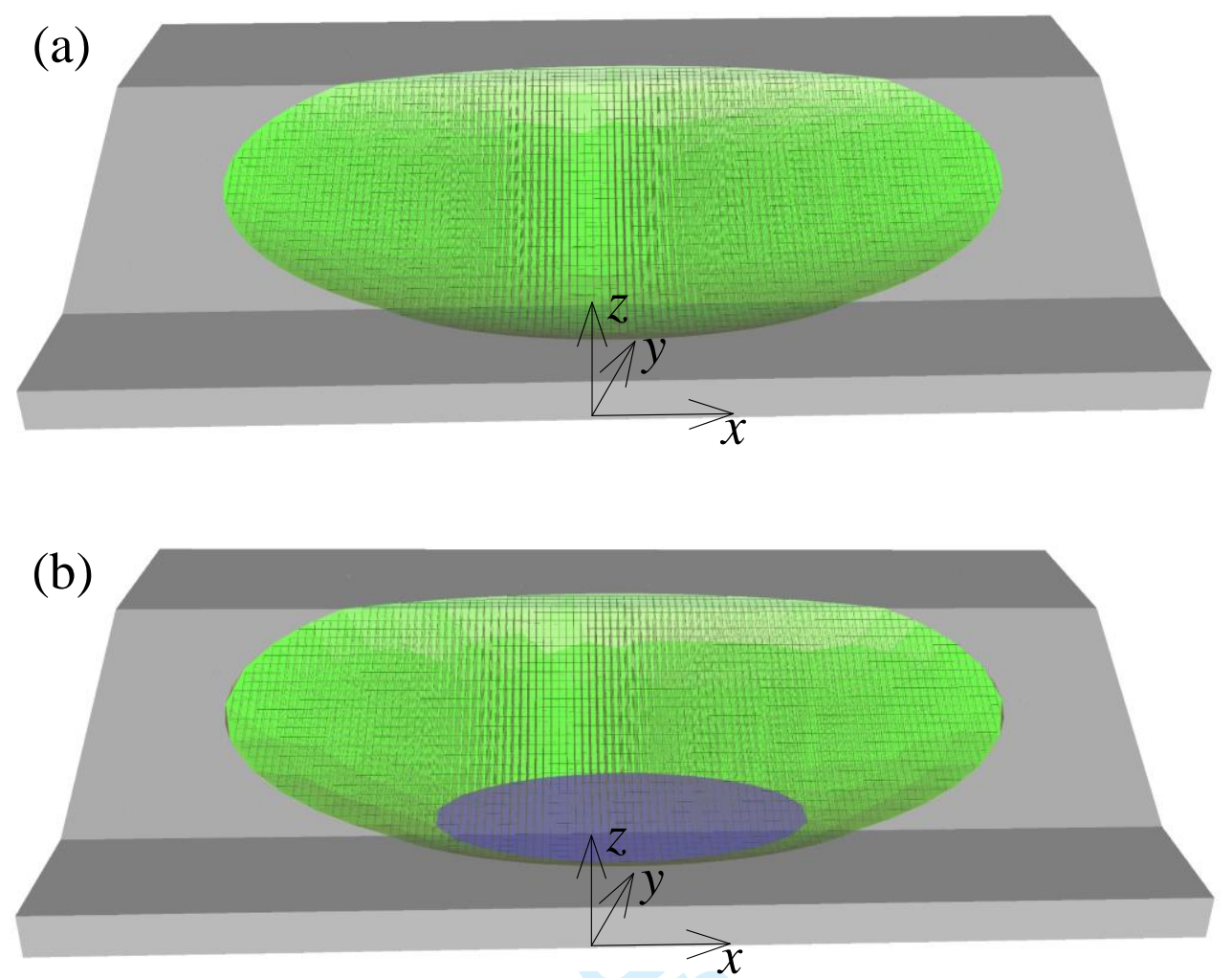

Fig. 4. Discretisation of the failure mass: (a) with an ellipsoidal failure surface; (b) with a composite failure surface containing a weak plane. 

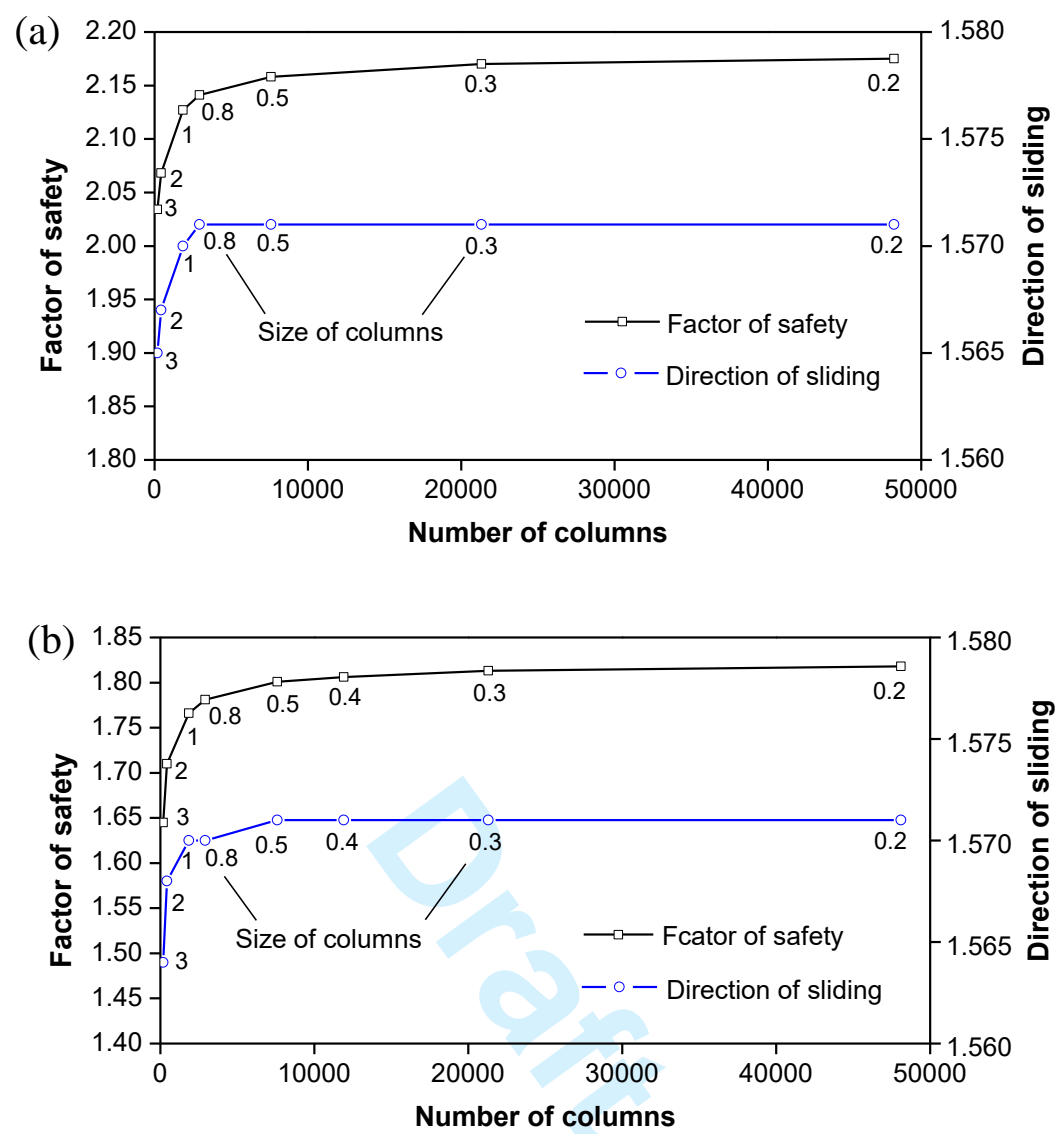

Fig. 5. Variation of calculated factors of safety and directions of sliding with the number of columns: (a) Case 1, Example 2; (b) Case 2, Example 2. 

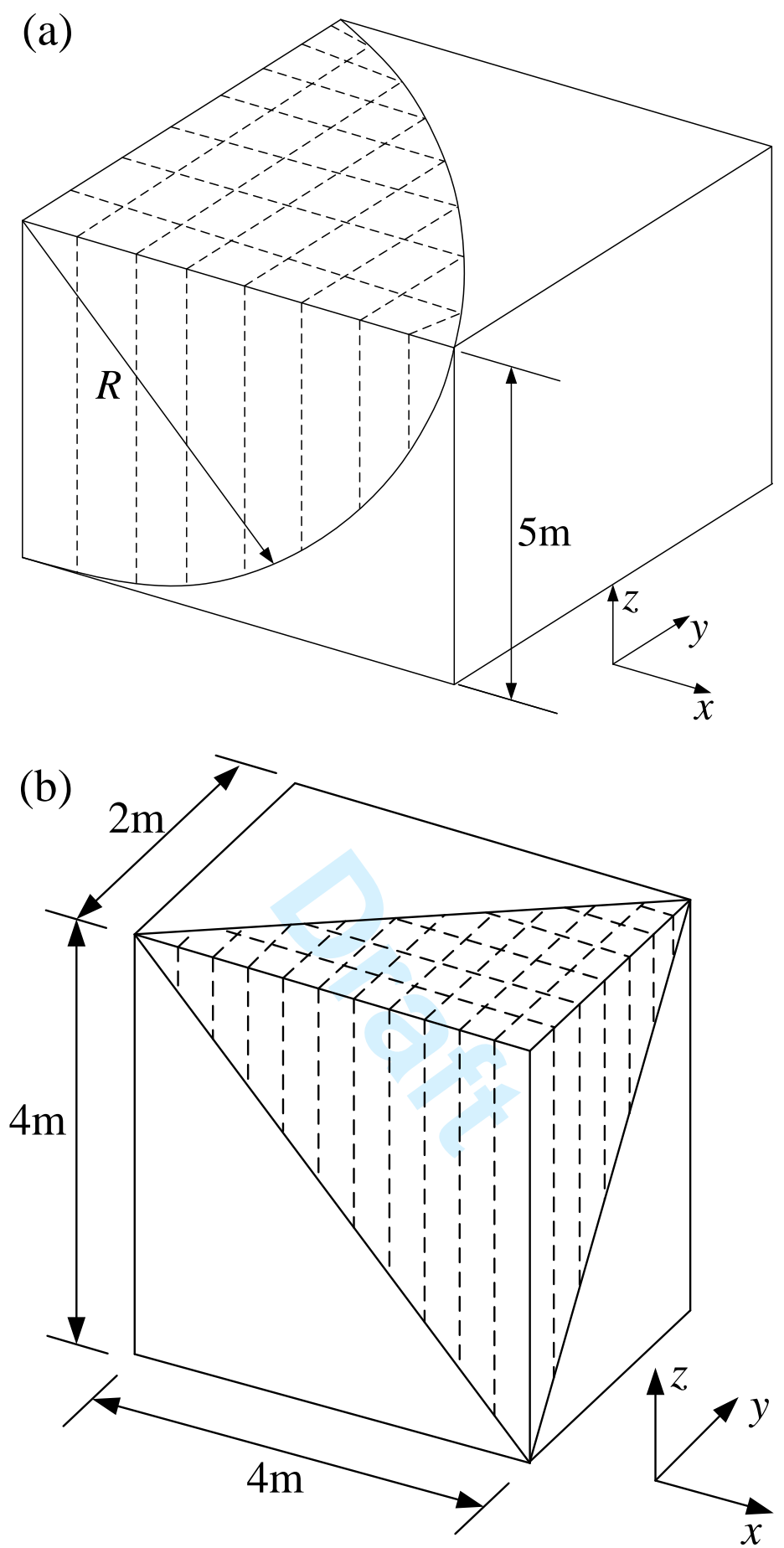

Fig. 6. Slope geometry for Example 3: (a) involving a symmetrical rotation failure; (b) involving an asymmetrical rigid block failure. 

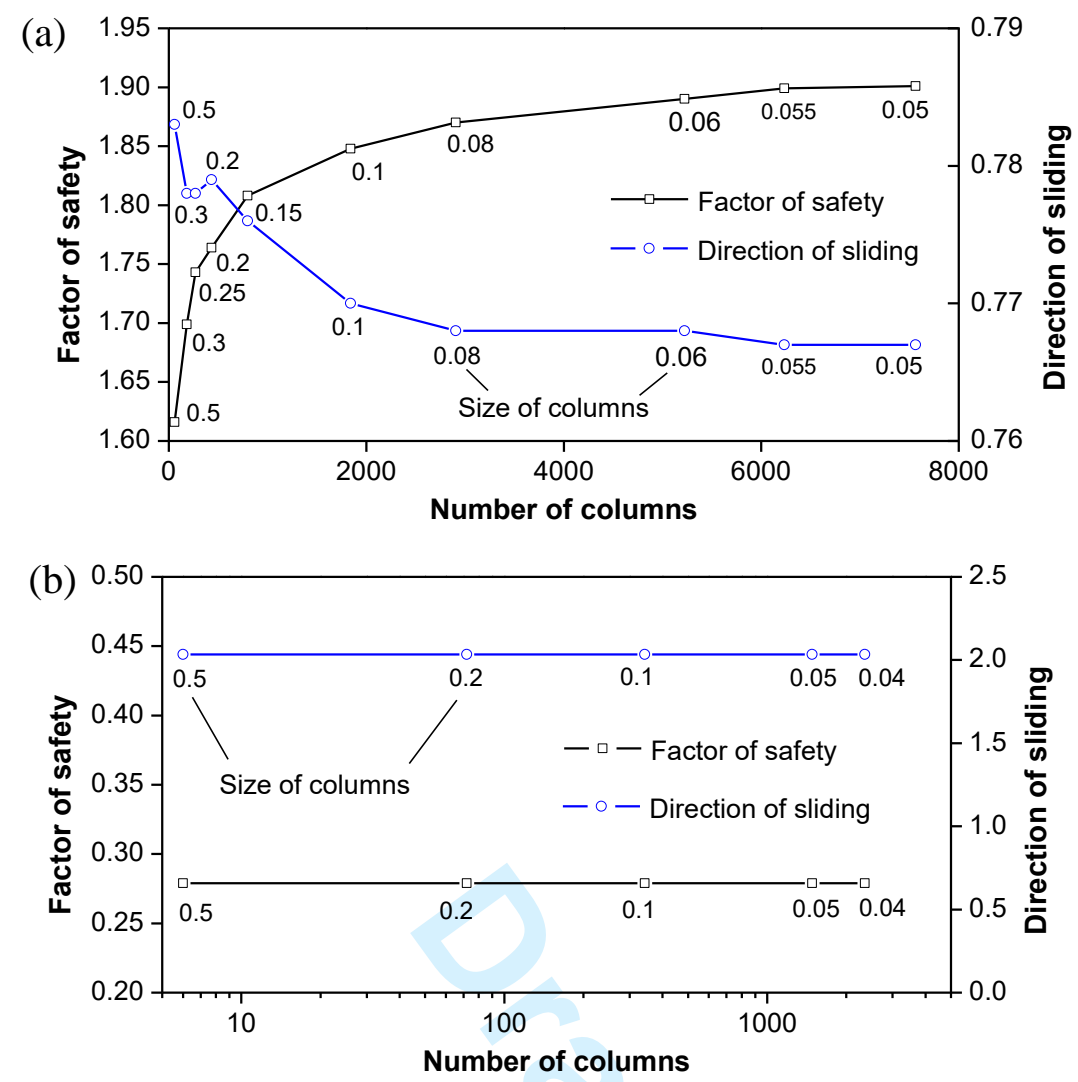

Fig. 7. Variation of calculated factors of safety and directions of sliding with column size: (a) Case 1, Example 3; (b) Case 2, Example 3. 
(a)

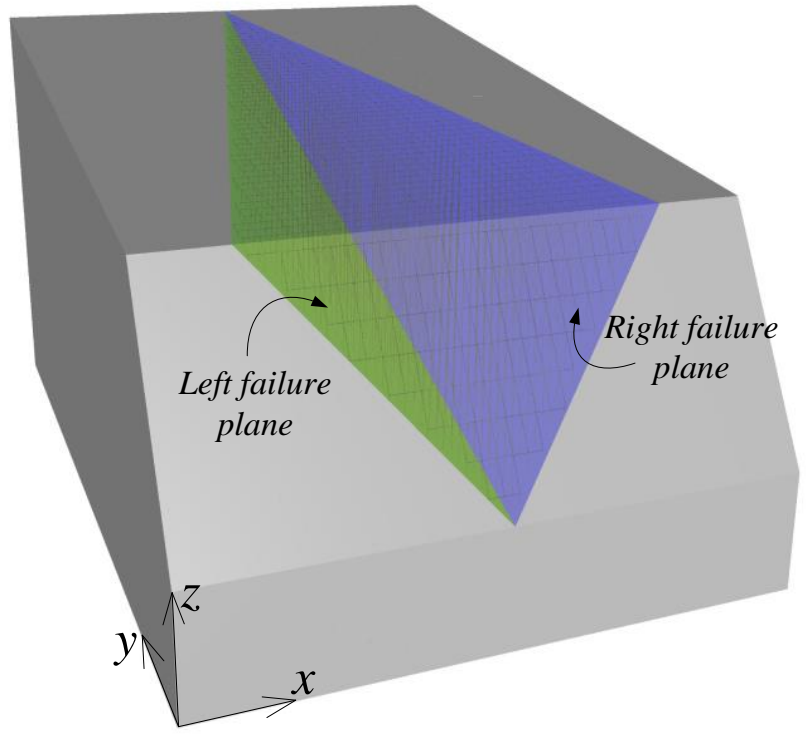

(b)

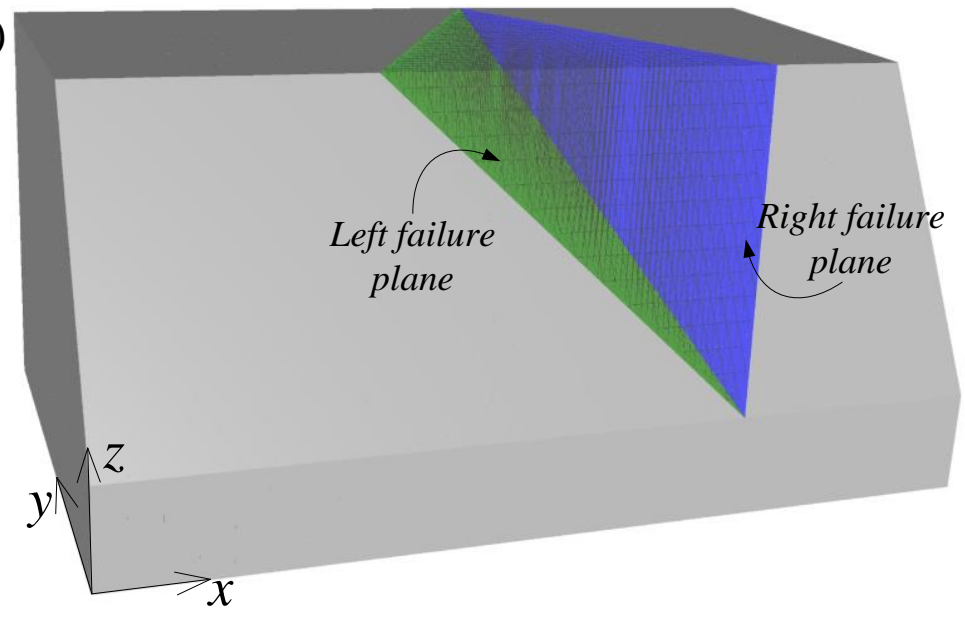

Fig. 8. The failure mass is divided into columns: (a) symmetrical wedge failure; (b) asymmetrical wedge failure. 

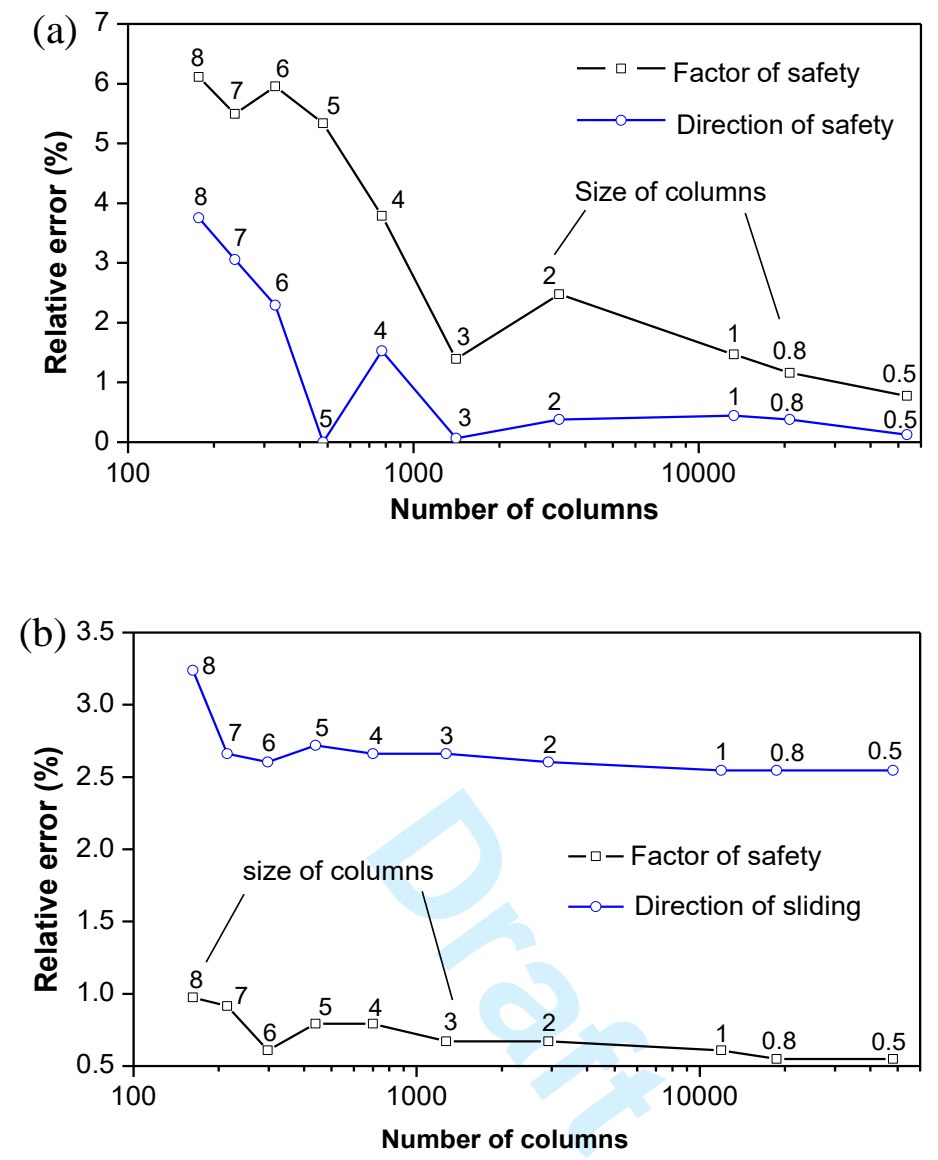

Fig. 9. Variation of relative errors in safety factor and sliding direction with the number of columns: (a) Case 1, Example 4; (b) Case 2, Example 4. 


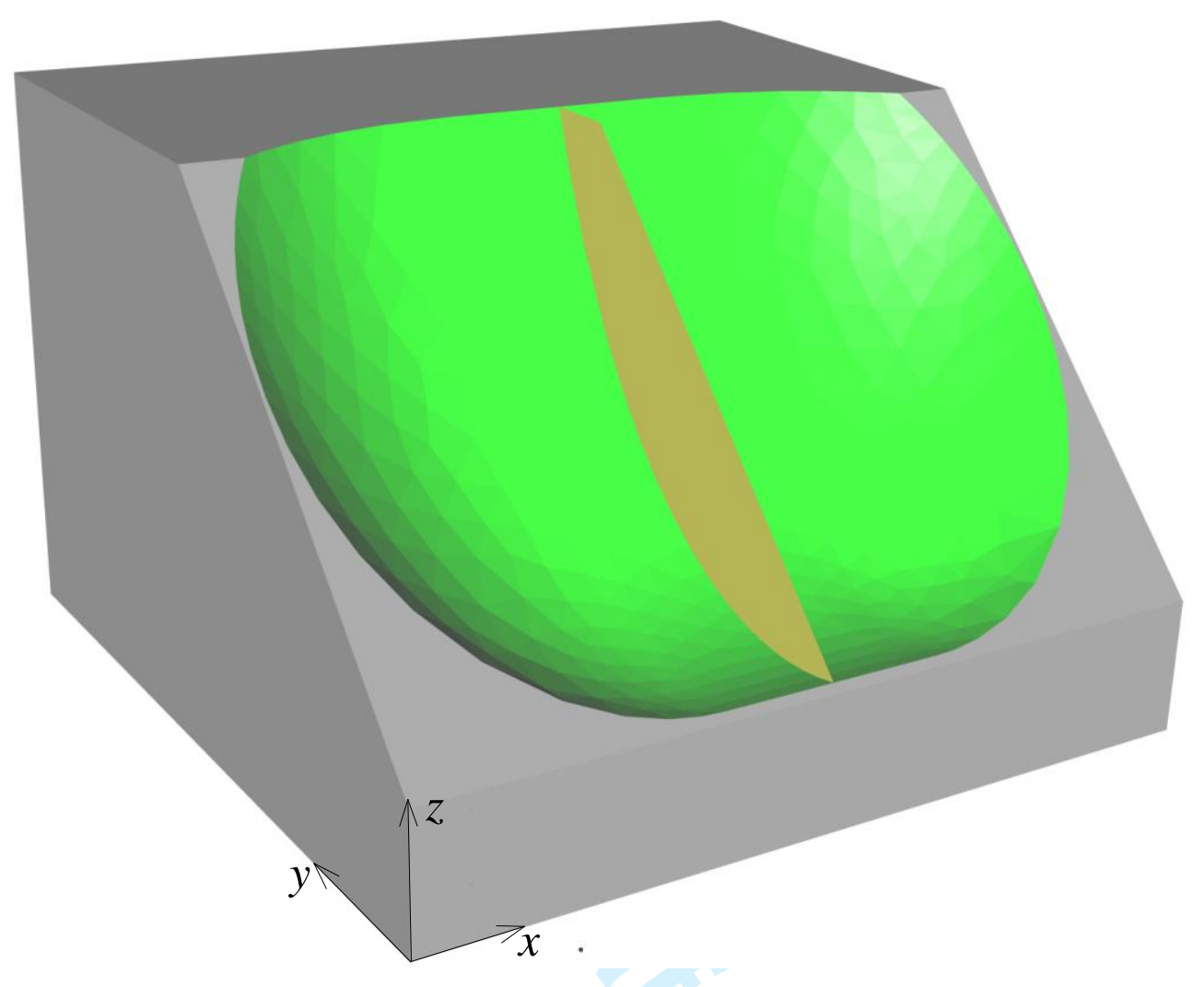

Fig. 10. Slip surface with the minimum factor of safety for Example 5. 

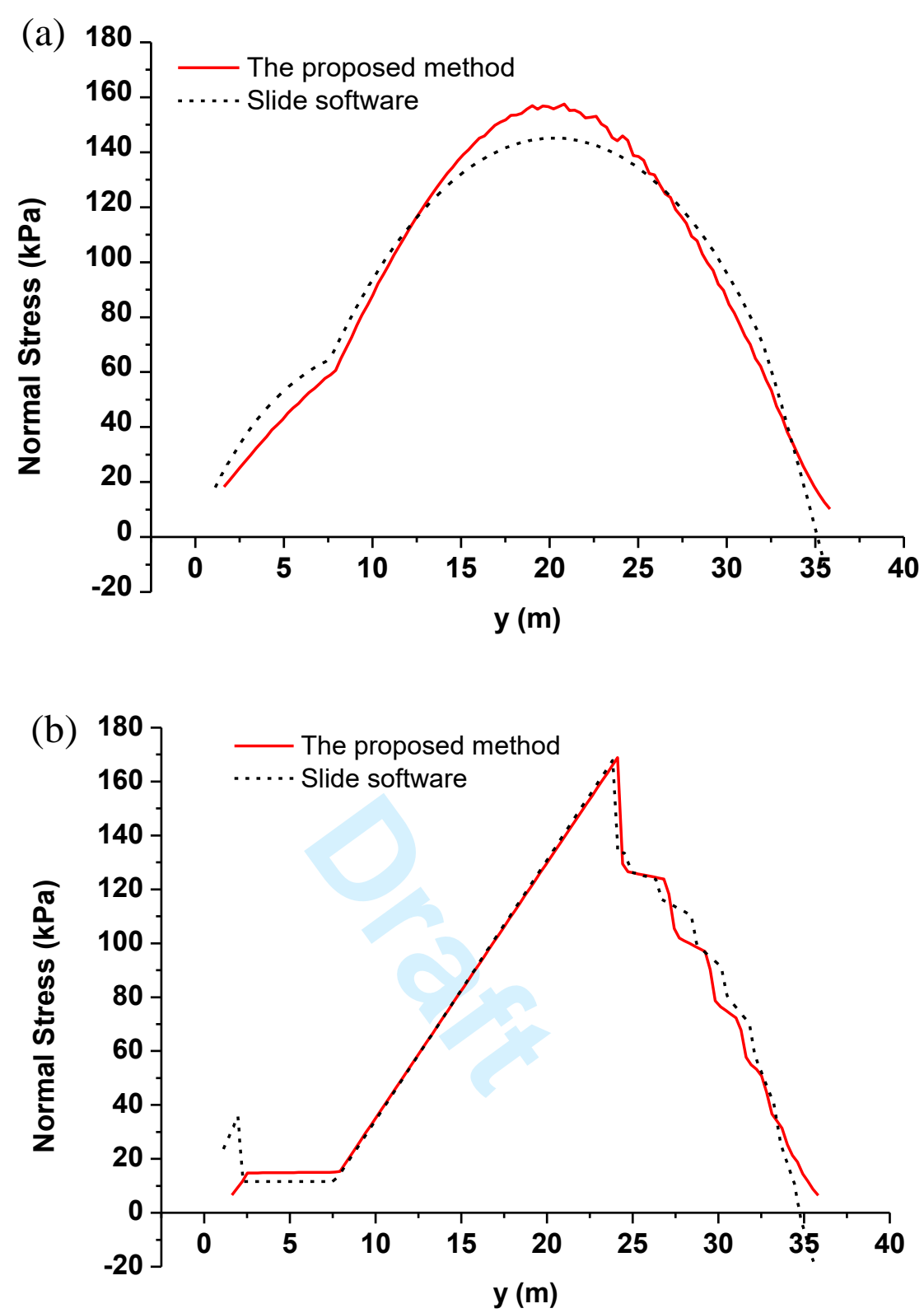

Fig. 11. Comparison of normal stresses distributions over the failure surfaces:

(a) Case 1, Example 1; (b) Case 2, Example 1. 

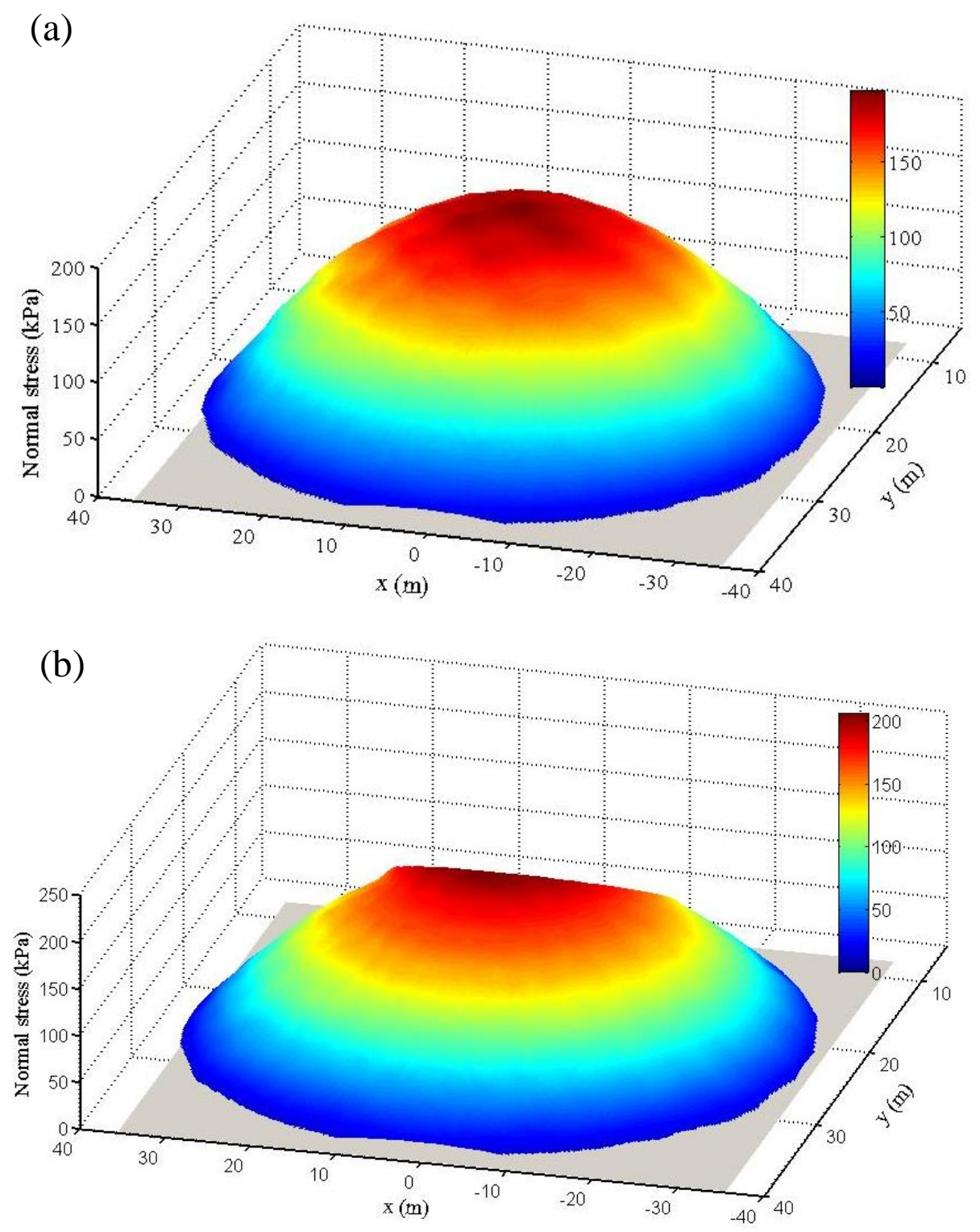

Fig. 12. Distributions of normal stresses over the failure surfaces: (a) Case 1, Example 2; (b) Case 2, Example 2. 

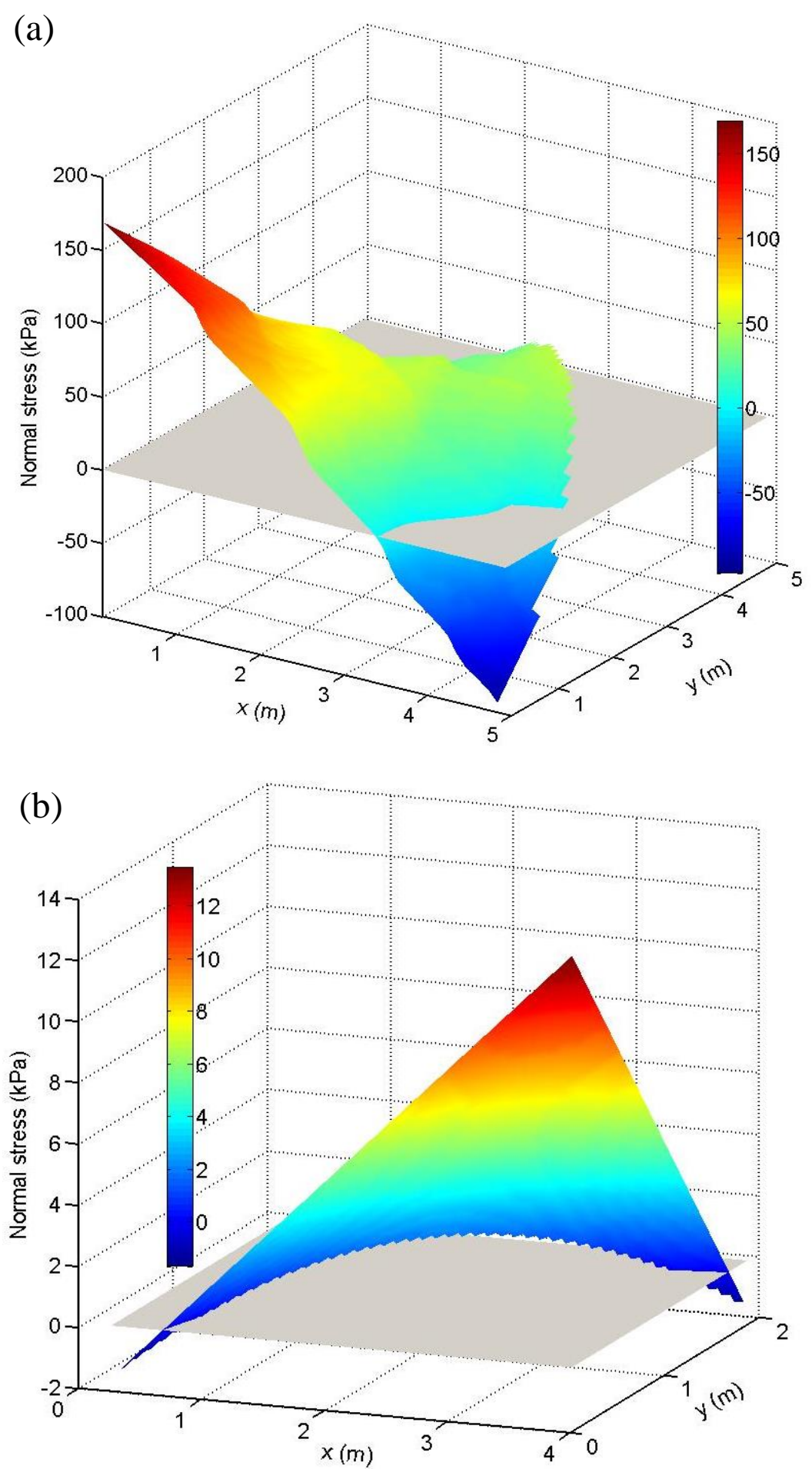

Fig. 13. Distributions of normal stresses over the failure surfaces: (a) Case 1, Example 3; (b) Case 2, Example 3. 
(a)

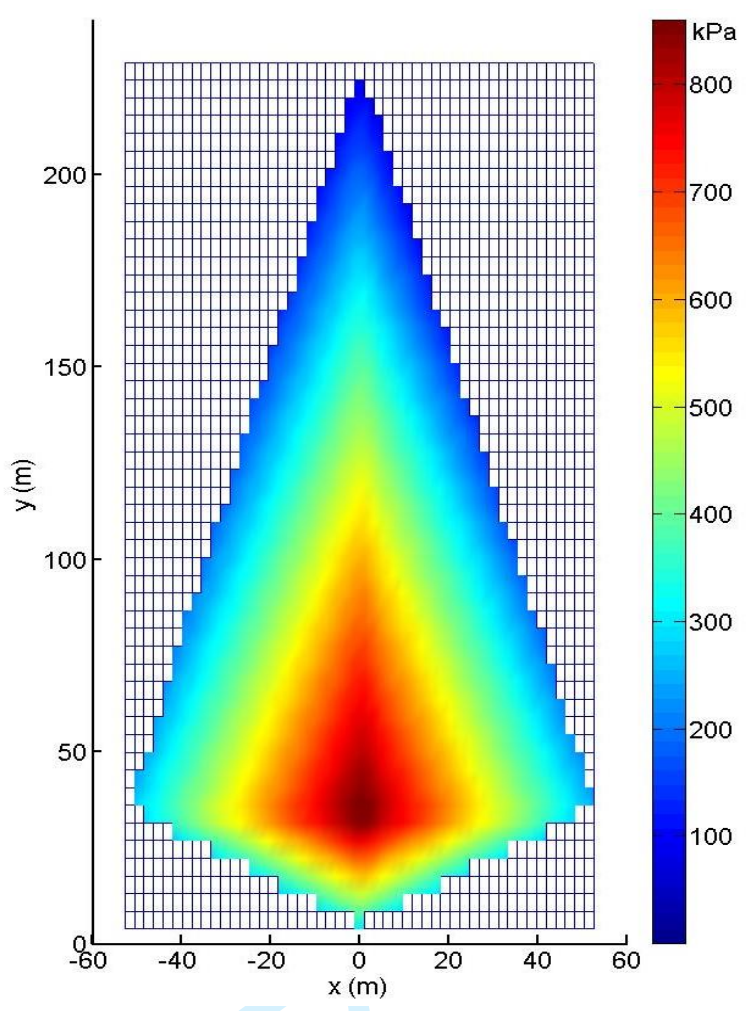

(b)

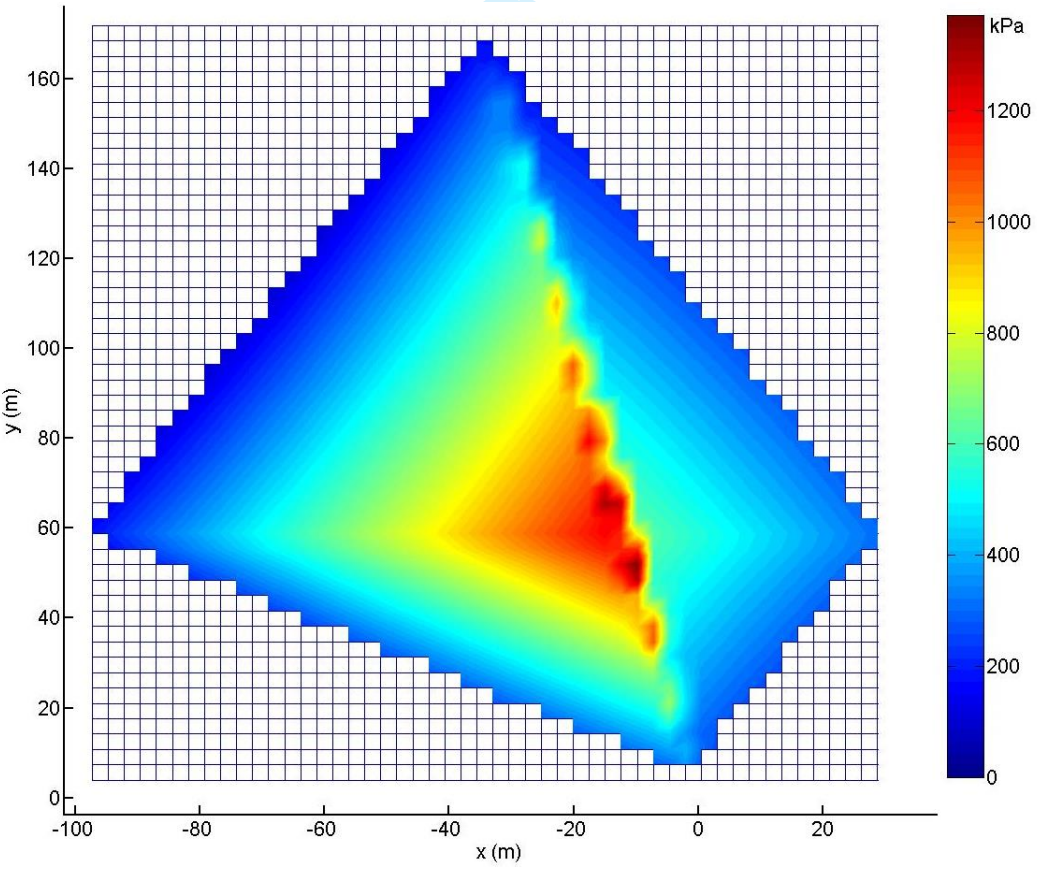

Fig. 14. Contours of normal stresses over the failure surfaces : (a) Case 1, Example 4; (b) Case 2, Example 4. 

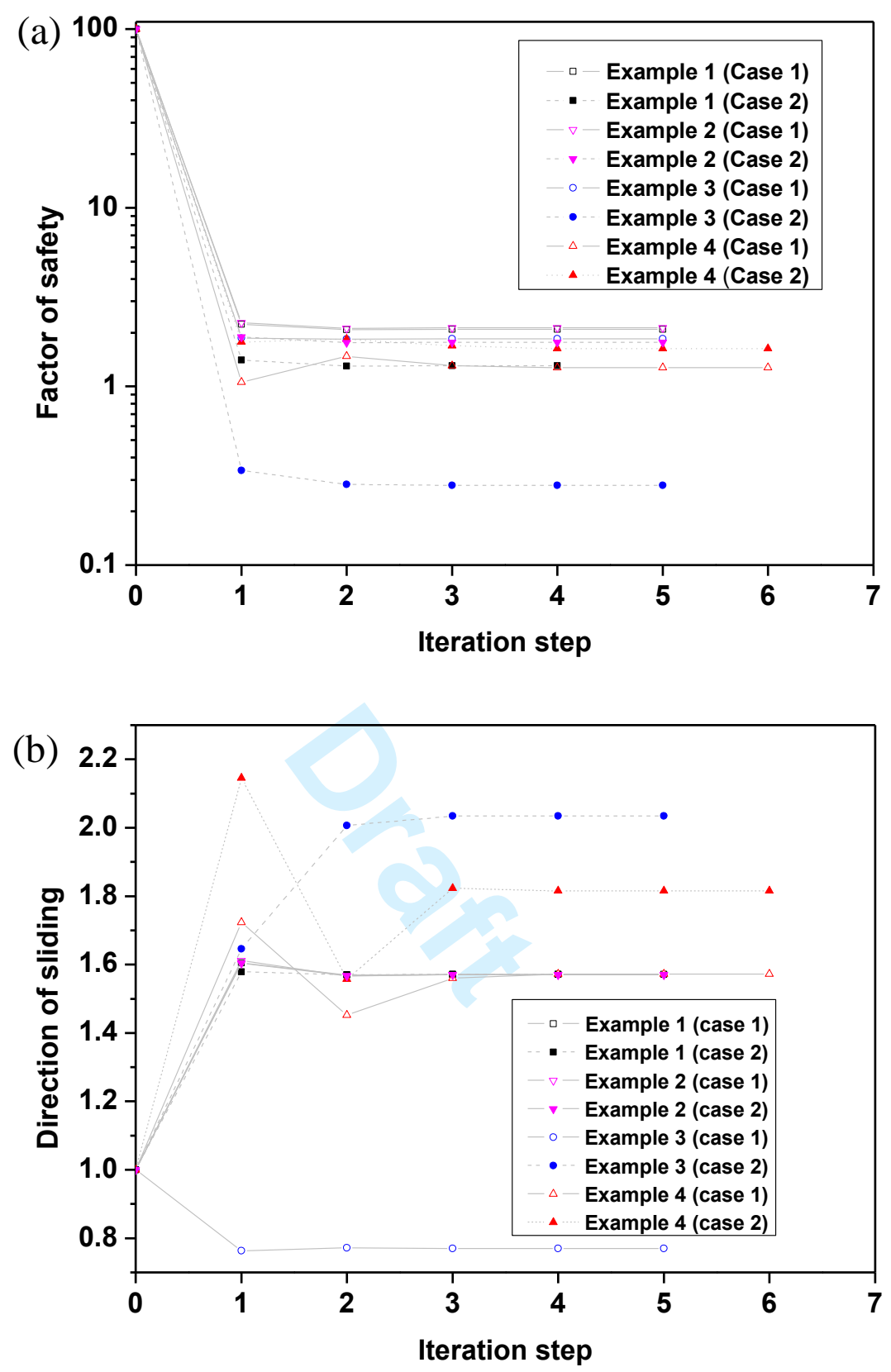

Fig. 15. (a) Calculated factor of safety versus iteration step number; (b) Calculated direction of sliding versus iteration step number. 

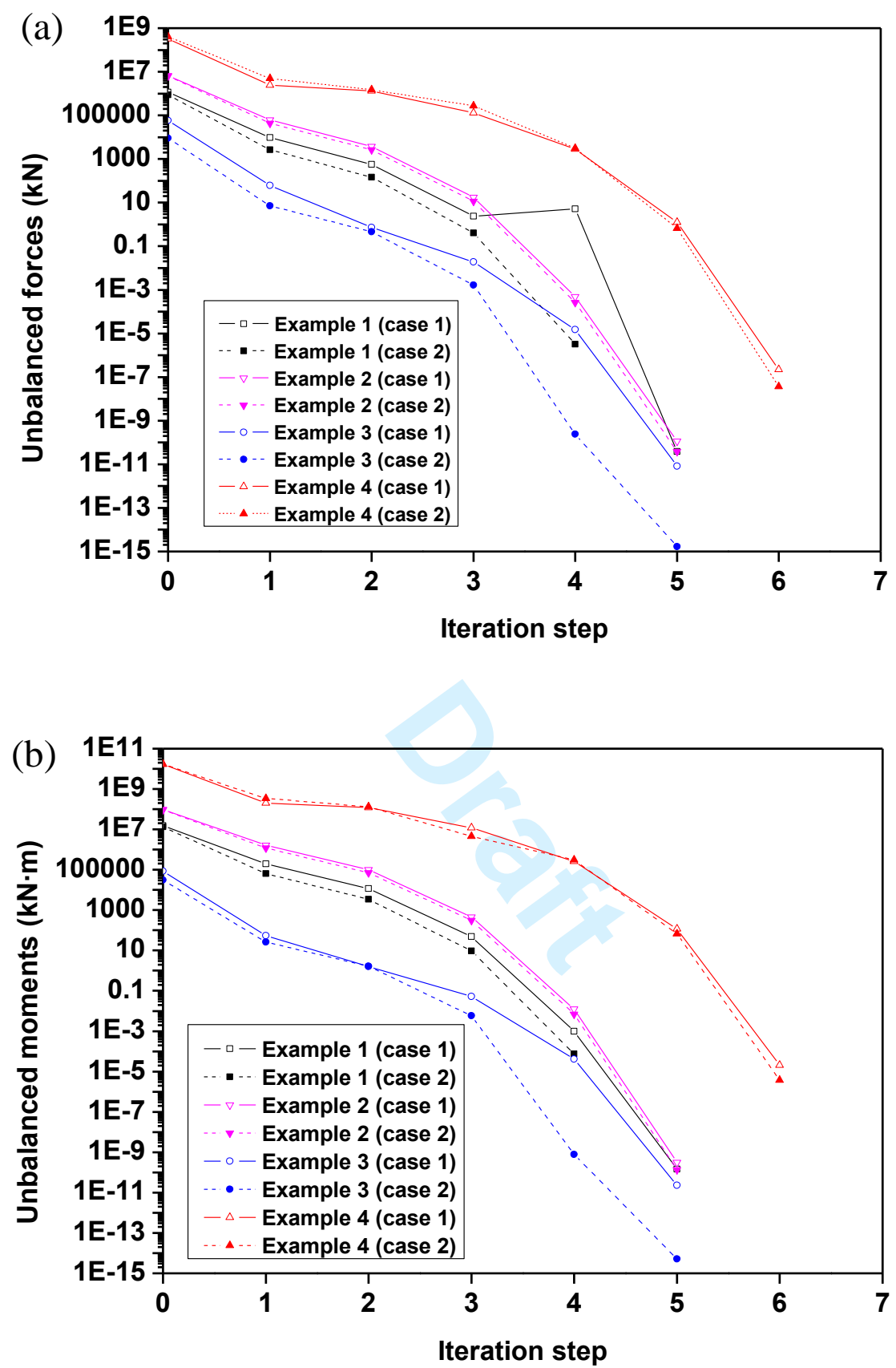

Fig. 16. (a) Calculated unbalanced force versus iteration step number; (b) Calculated unbalanced moment versus iteration step number. 


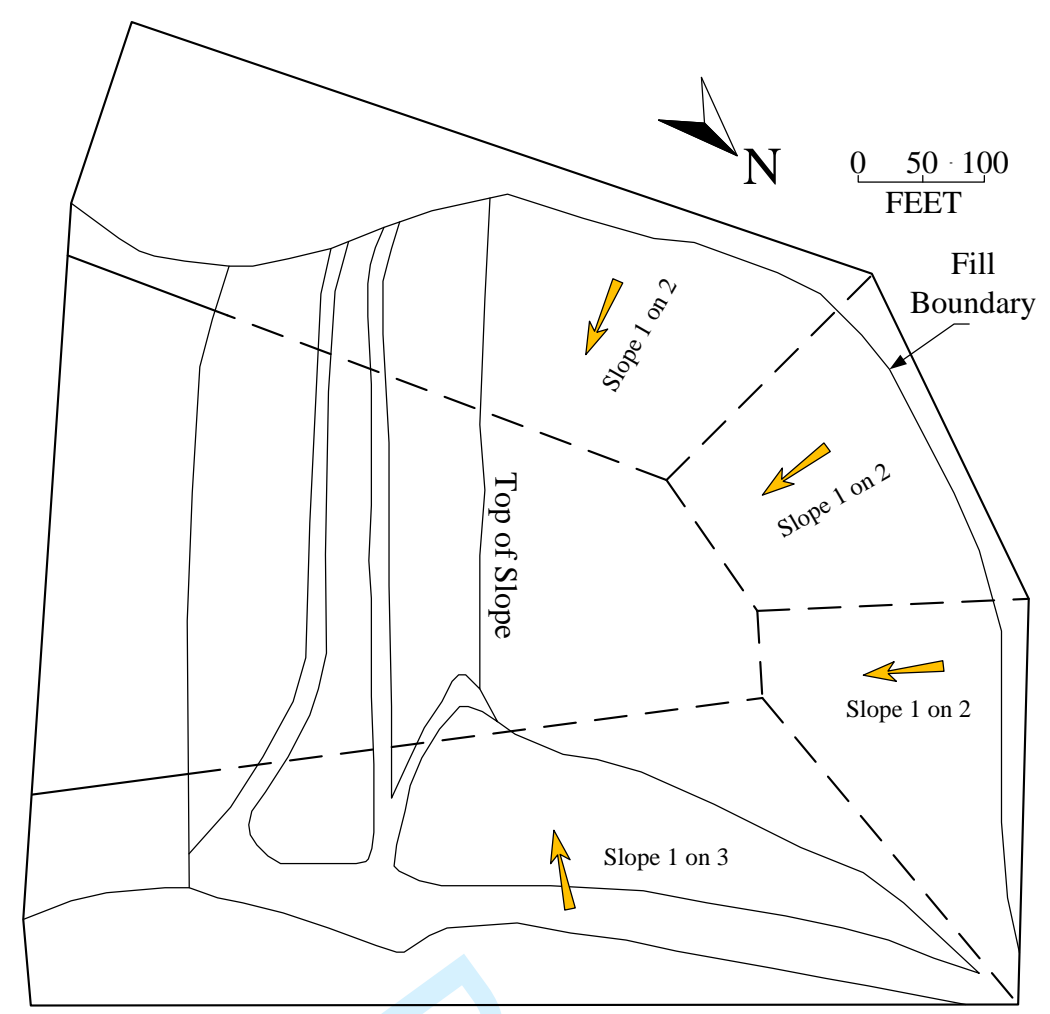

Fig. 17. Plan view of Unit B-19, Phase I-A landfill. 


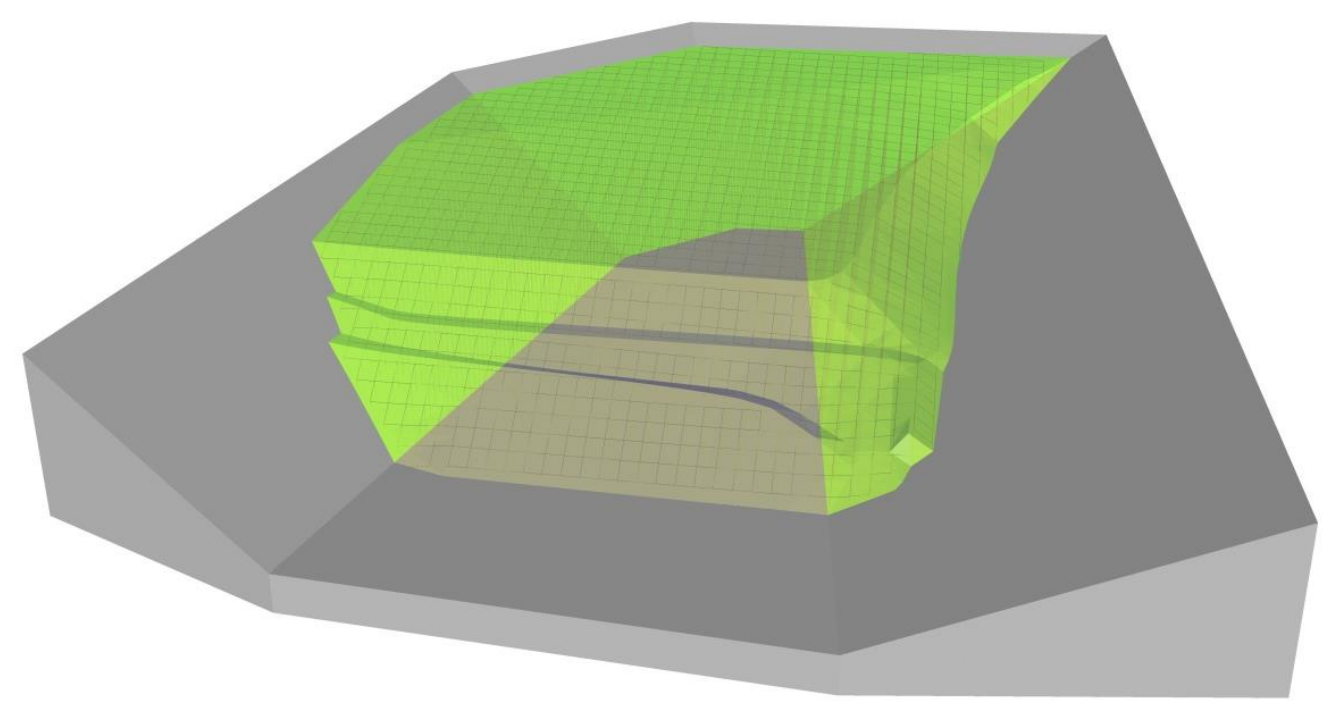

Fig. 18. 3-d model and the division of columns in the chosen waste landfill slope. 


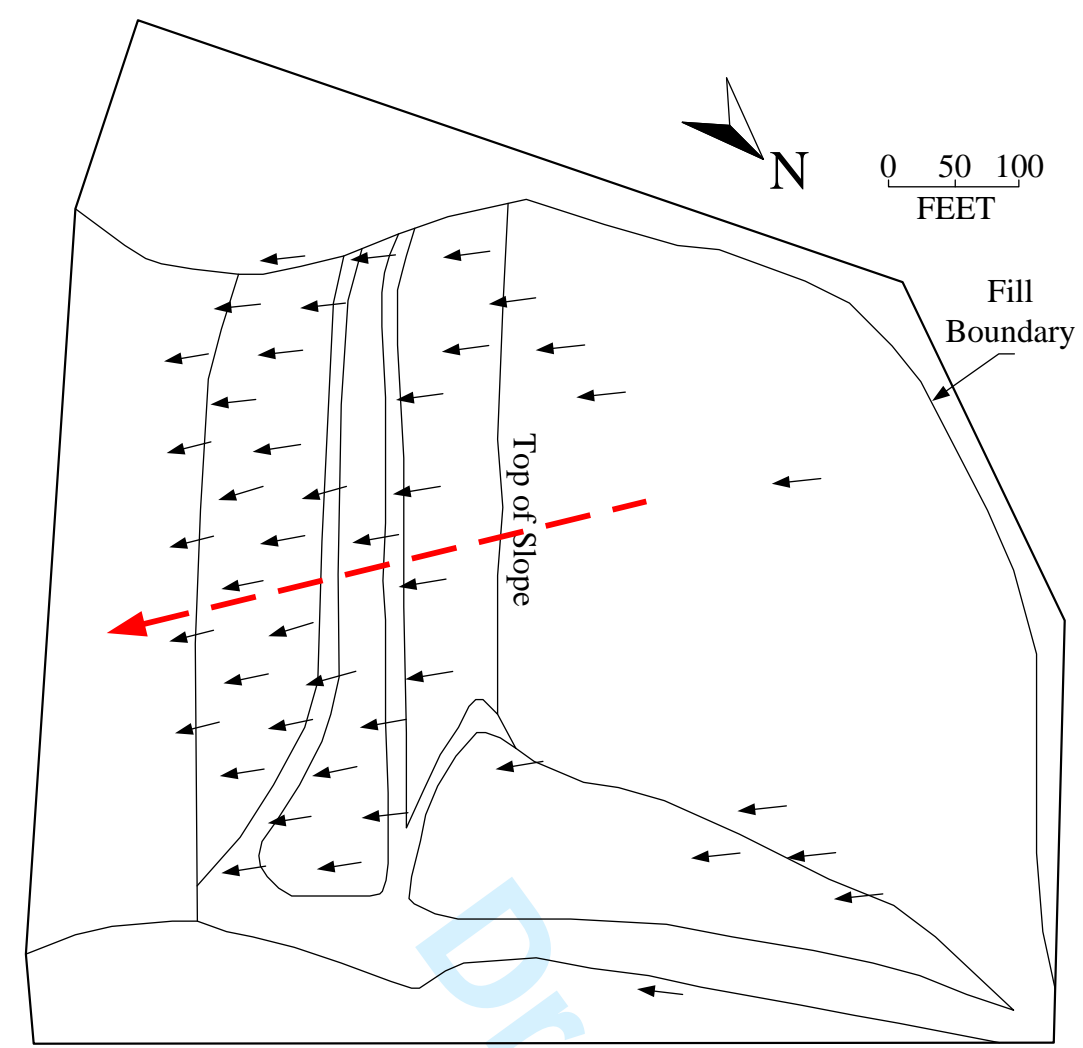

$\longleftarrow$ On-site measurements of horizontal displacement vectors of the landfill slope.

--- Calculated direction of sliding of the landfill slope, $\beta=S 57^{\circ} E$.

Fig. 19. Calculated direction of sliding and horizontal displacement vectors of the chosen landfill slope. 

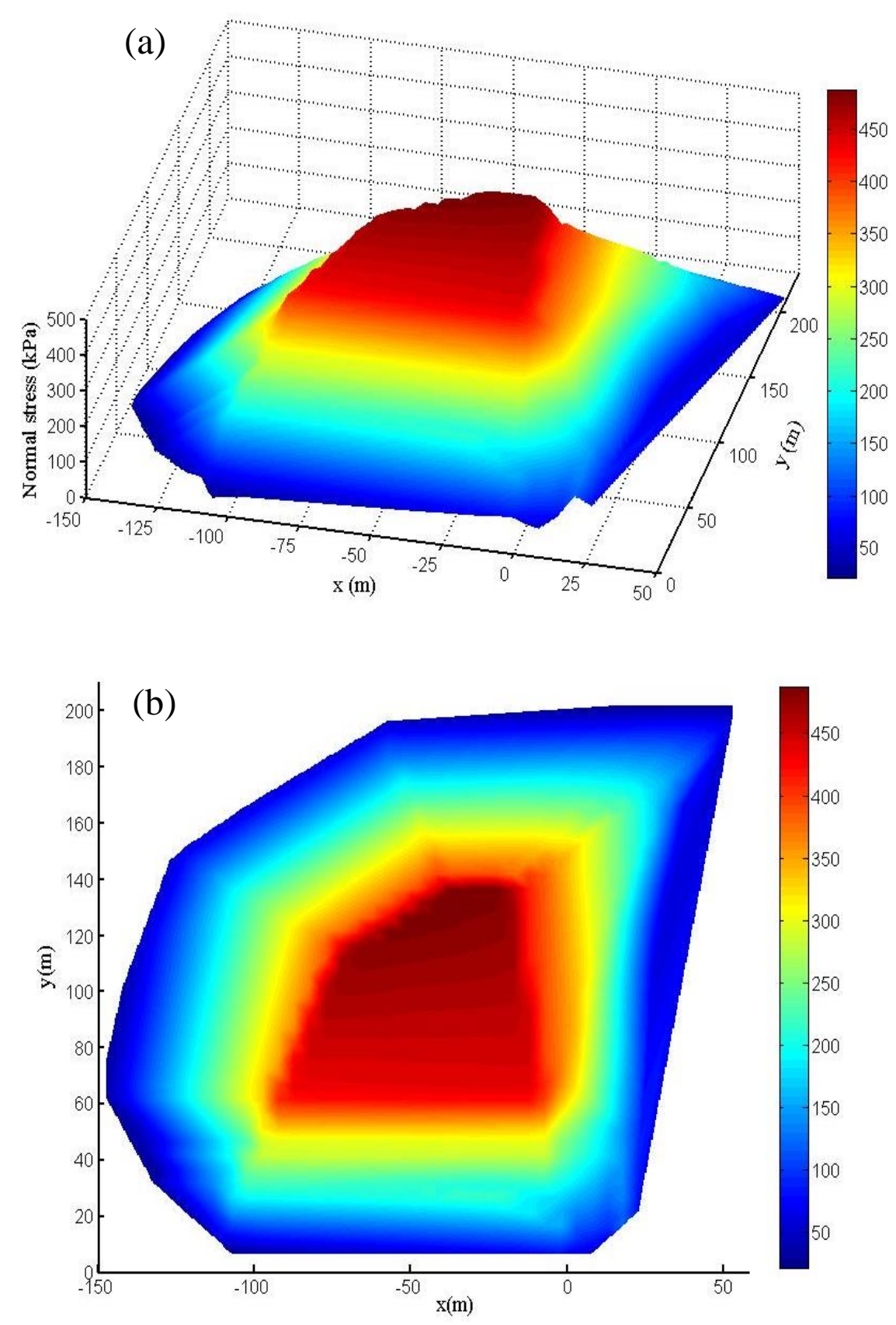

Fig. 20. Normal stresses over the failure surfaces : (a) 3-d view; (b) plan view. 